\title{
Evaluation of Shear Crack Width in I-Shaped Prestressed Reinforced Concrete Beams
}

\author{
Sudhira De Silva ${ }^{1}$, Hiroshi Mutsuyoshi ${ }^{2}$ and Eakarat Witchukreangkrai ${ }^{3}$
}

Received 8 November 2007, accepted 8 September 2008

\begin{abstract}
Recently, Prestressed Reinforced Concrete (PRC) has been accepted as a reasonable structural member that permits cracking. A PRC member is a visible design alternative to either reinforced concrete (RC) or fully prestressed concrete (PC). In Japan, PRC has been widely used for bridge structures because it is economical. PRC members are generally designed to allow cracking under full service loads. Flexural cracking in PRC beams has been already studied and the flexural crack width can be accurately predicated by equations available in the present codes (ACI, CEB-FIP, JSCE, etc.). On the other hand, shear cracking behavior in PRC members is barely understood. The objective of the present study is, therefore, to experimentally explore the shear cracking behavior of PRC beams. Three I-shaped RC and four Ishaped PRC beams were tested under four-point monotonic loading. The experimental program was carried out focusing on the influence of prestressing force, side concrete cover, stirrup spacing, bond characteristics of stirrup and the amount of longitudinal reinforcement on shear crack width. The study revealed that the prestressing force significantly reduced shear crack width in PRC beams as compared to RC beams. In addition, an equation was proposed to calculate shear crack width in RC and PRC members. The proposed formula for shear crack width shows better correlation between calculated values and experimental data than the other formulae.
\end{abstract}

\section{Introduction}

Prestressed concrete (PC) structures can generally be categorized into three classes (ACI-ACSE Committee 423 1999) according to cracking criteria. The first class is defined as fully prestressed members since no tensile stresses are permitted in concrete under full service loading. Fully prestressed concrete girders have been widely used in bridge spans exceeding about $60 \mathrm{~m}$. However, one of the drawbacks of using fully prestressed concrete beams is that the high-strength materials required for prestressing are relatively expensive. In the second class of PC structures, an allowable level of tensile stress is permitted in the concrete under full service loading, while cracks are not permitted. The third class is defined as partially prestressed concrete (PPC). PPC is made by introducing a low amount of non-prestressed steel into a fully prestressed member. On the other hand, if a certain amount of prestressing force is introduced into reinforced concrete (RC), it results in an alternative member called prestressed reinforced concrete (PRC). In Japan, PRC beams have been

${ }^{1}$ Senior Lecturer, Department of Civil and Environmental Engineering, Faculty of Engineering, University of Ruhuna, Sri Lanka.

E-mail:sudhira@cee.ruh.ac.lk

${ }^{2}$ Proffessor, Department of Civil and Environmental Engineering, Graduate School of Science and Engineering, Saitama University, Japan.

${ }^{3}$ Engineer, Civil Engineering, Technology Division, Shimizu Corporation, Japan. widely used in bridge spans with lengths ranging from around $40 \mathrm{~m}$ to $60 \mathrm{~m}$ because they are economical.

In PRC, cracks are permitted within allowable limits of crack width under full service loading. PRC members incorporate non-prestressed reinforcements as well as prestressed steels, and both contribute to member resistance. PRC members demonstrate that there are solutions intermediate between fully prestressed concrete and ordinary reinforced concrete offering numerous advantages. For example, permitting tensile stresses and cracking in the concrete allows for more latitude in deciding the amount of prestressing force required to achieve optimum structural performance under particular loading conditions. PRC members are excellent as a means of obtaining a suitable degree of control over cracking. The small amount of prestressing steel used to provide this crack control is insufficient to ensure the required strength, so additional non-prestressed reinforcement is used. PRC members result in more economical design with smaller cross sections and a reduced amount of prestressing steel. The non-prestressed reinforcement used in PRC members enhances strength and also controls the formation of cracks and crack width.

Cracking behavior, control of crack width and the distribution of crack spacing are significant factors in the design of PRC structural members. The cracking behavior of RC beams and PRC beams has been investigated in many studies over the last five decades (Adebar and Leeuwen 1999; De Silva 2005; Frosch 1999, Hassan et al., 1991, Kakuta, Y., et al., 1970, Krishna Mohan Rao and Dilger 1992, Piyasena et al., 2004, Oh and Kang 1987). Most of these studies have focused on flexural 
cracking behavior, while very few have been concerned with shear cracking. Most existing design methodologies evaluate the flexural crack width in $\mathrm{RC}$ and PRC members, whereas there is a little mention of shear crack width in RC members (Adebar and Leeuwen 1999; Fukuyama et al., 2000; Shinomiya and Watanabe 2002). Indeed, there is no existing design methodology for evaluating shear crack width in PRC members. The equations stipulated in the ACI (2002), CEB-FIP Model Code (1978) and Japan Society of Civil Engineers (JSCE, 2002) codes give very accurate determinations of flexural crack width in RC and PRC members. However, there are no specific prescribed design guidelines for evaluating shear crack width in PRC members. Further, there has yet been no clarification of the parameters that influence shear crack width in PRC members.

Recently, shear cracking in concrete structures has become an important issue concerning the durability of concrete structures. In Japan, the case of a PRC bridge that developed serious cracks including shear cracks just after completion was reported (JSCE Mid-Term Report (2005)). This emphasizes the importance of investigating methods of controlling shear crack width in both RC and PRC beams. For RC beams, control has been achieved by limiting stirrup strain as defined in the ACI and the JSCE standard specifications. The JSCE standard specification and previous studies (Hsiung and Frantz 1985; Hassan et al., 1991; Witchukreangkrai et al., 2004; De Silva 2005) show that strain in the web reinforcement is the most significant parameter affecting shear crack width in RC beams. The strain developed in the web reinforcement is associated with the characteristics of the stirrups such as bar diameter, spacing, orientation with respect to the member axis and bonding properties, concrete strength, web width, the ratio of shear span to effective depth and the amount of longitudinal reinforcement. The recent studies (Hsiung and Frantz 1985; Zararis and Papadakis 2001; Zararis 2003) have indicated that adjusting the quantity of stir-

Table 1 Experimental variables.

\begin{tabular}{|c|c|c|c|c|}
\hline \multirow[t]{2}{*}{ Beam \# } & \multicolumn{2}{|c|}{$\begin{array}{c}\text { Non-prestressed } \\
\text { reinforcement }\end{array}$} & \multirow{2}{*}{$\begin{array}{l}\text { Effective depth } \\
\text { to prestressing } \\
\text { bar }(\mathrm{dp}, \mathrm{mm})\end{array}$} & \multirow{2}{*}{$\begin{array}{l}\text { Stirrup } \\
\text { spacing } \\
(\mathrm{mm})\end{array}$} \\
\hline & Top & Bottom & & \\
\hline IRC-1 & \multirow{7}{*}{$\begin{array}{c}4 \mathrm{D} 22 \\
\left(d s^{\prime}=\right. \\
40 \mathrm{~mm}) \\
f_{y}^{\prime}= \\
400 \\
\mathrm{MPa}\end{array}$} & \multirow{6}{*}{$\begin{array}{c}4 \mathrm{D} 25 \\
(d s=450 \mathrm{~mm}) \\
f_{y}=685 \mathrm{MPa}\end{array}$} & \multirow{2}{*}{ - } & 125 \\
\hline IRC-2 & & & & $125^{\S}$ \\
\hline IRC-3 & & & $250 *$ & 125 \\
\hline IPRC-1 & & & \multirow[b]{4}{*}{250} & 125 \\
\hline IPRC-2 & & & & 225 \\
\hline IPRC-3 & & & & $125^{\dagger}$ \\
\hline IPRC-4 & & $\begin{array}{c}2 \mathrm{D} 29 \text { and } \\
2 \mathrm{D} 38 \\
(d s=450 \\
\mathrm{mm}) \\
f_{v}=685 \mathrm{MPa}\end{array}$ & & 125 \\
\hline
\end{tabular}

\footnotetext{
* no prestressing

$\S$ maximum side concrete cover $(\mathrm{c}=69 \mathrm{~mm})$

${ }^{\dagger}$ plain stirrups
}

rups only may not be sufficient to control shear cracking, but that the amount of longitudinal reinforcement can have a significant influence on the opening of critical shear cracks. Thus there have been a few studies (Yoon et al., 1996; Hassan et al., 1991; Tompos and Frosch 2002) of the parameters that affect shear crack width in $\mathrm{RC}$ members, but barely any investigation of such parameters for PRC members.

In order to focus on only shear cracks that occur in the web, it is necessary to design test beams that will fail with many shear cracks in the shear span. Therefore, test beams with I-shaped cross sections, consisting of both RC and PRC beams, were used in the present study because the thinner web in an I-section induces larger shear stresses, which then cause many shear cracks in the web independent of flexural cracks. It was expected that the beams would fail with parallel shear cracks distributed uniformly throughout the web over the entire shear span. The objective of this study is to investigate experimentally the effects of different parameters on the shear crack width of these I-shaped RC and PRC beams. The experimental variables include prestressing force, side concrete cover, stirrup spacing, stirrup bonding characteristics and the amount of longitudinal reinforcement. In addition, simplified rational equations were proposed to calculate shear crack spacing and shear crack width in RC and PRC beams. The proposed equations are compared comprehensively with experimental results such as crack spacing and crack width.

\section{Experimental procedure}

\subsection{Test details}

In order to investigate the influence of various parameters including prestressing force on shear crack width in PRC beams, an experimental program was carried out as follows. The prestressing force (or compressive stress in concrete due to prestress, $\sigma_{\mathrm{c}, \mathrm{pc}}$ ), side concrete cover, stirrup spacing, type of stirrup and amount of longitudinal reinforcement were the main experimental parameters (Table 1). The test beams consisted of three RC and four PRC beams with I- shaped cross sections. These test beams were designed in accordance with the JSCE standard specification (JSCE 2002). The total beam length was $3600 \mathrm{~mm}$. Cross-sectional details and typical layouts are shown in Figs. 1 and 2, respectively. The mechanical properties of the non-prestressed steel and prestressed steel used in the experiment are listed in Table 2. The material properties (i.e., yield strength, ultimate strength and young's modulus) of high-strength steels (USD 685) and prestressing steel were provided by the manufacturer and the material properties of normal steel (SD 345) were experimentally determined. In all the test beams, two different sizes of stirrup bars were provided: D6 $(\mathrm{D}=$ deformed bar, $6=$ diameter in $\mathrm{mm}$ ) and D10. The D6 bars were used in the left span of the beams while the D10 bars were used in the right span to ensure that the main shear crack would occur in 
the left span. Ready mixed concrete with a maximum aggregate size of $20 \mathrm{~mm}$ was used for all beams.

\subsection{Instrumentation}

A total of 49 steel strain gages were placed on the stirrups to measure stirrup strains in the shear span. The locations of the strain gages are shown in Figs. 2 and $\mathbf{3}$. Seven strain gages were attached at equal spacing in each stirrup. This is necessary because the random occurrence of shear crack may influence stirrup strains depending on the location of cracks. This arrangement allows clarification of the relationship between the strains of the stirrups and the width of shear cracks. In addition, strain gages were attached to the tensile reinforcements and the prestressing tendon at mid-span. Contact chips were pasted on the surface of each beam

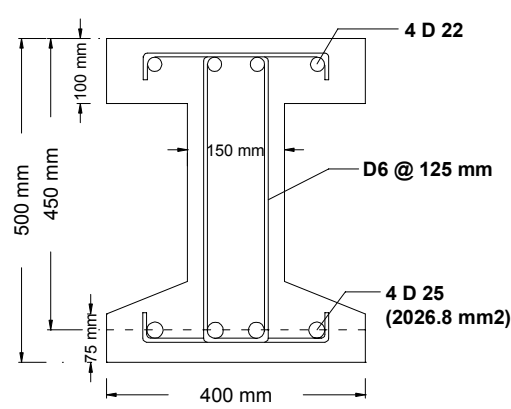

IRC -1

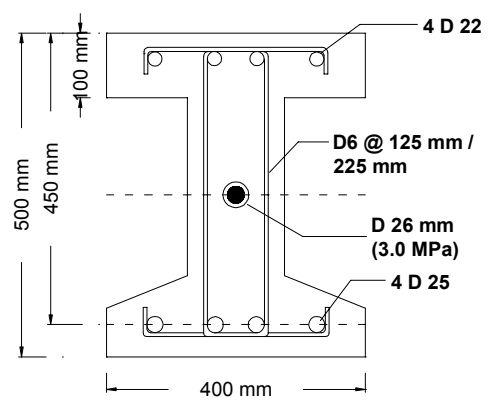

IPRC-1 and IPRC-2

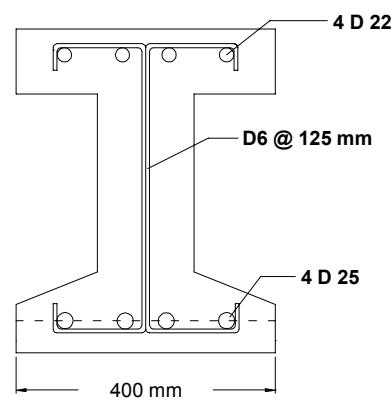

IRC -2

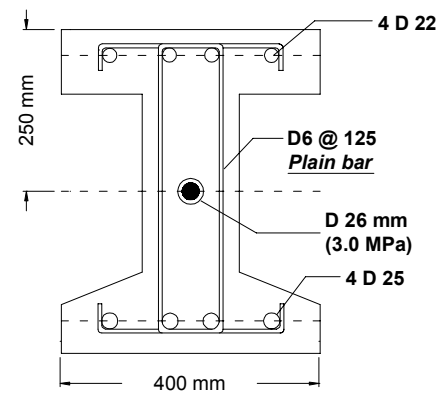

IPRC -3

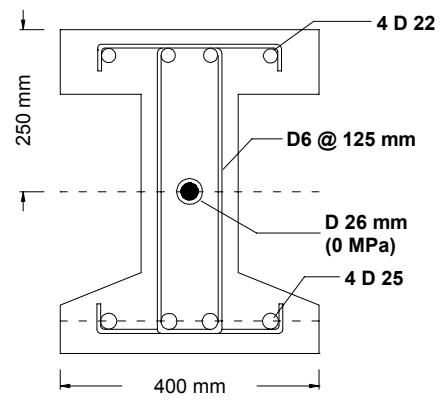

IRC -3

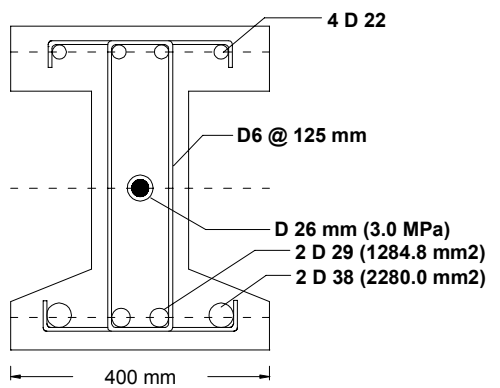

IPRC -4

Fig. 1 Cross sectional details of beams.

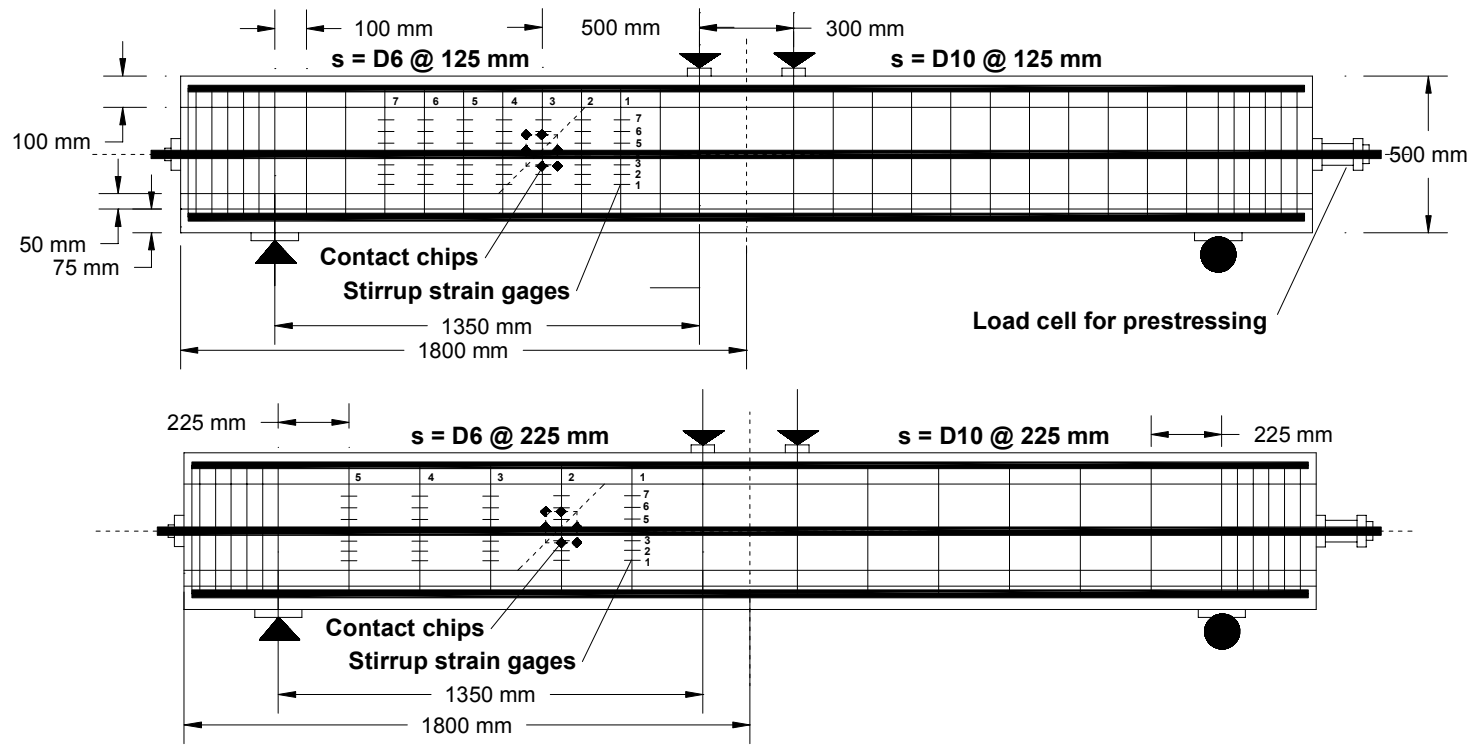

Fig. 2 Details of test beams and loading arrangement. 


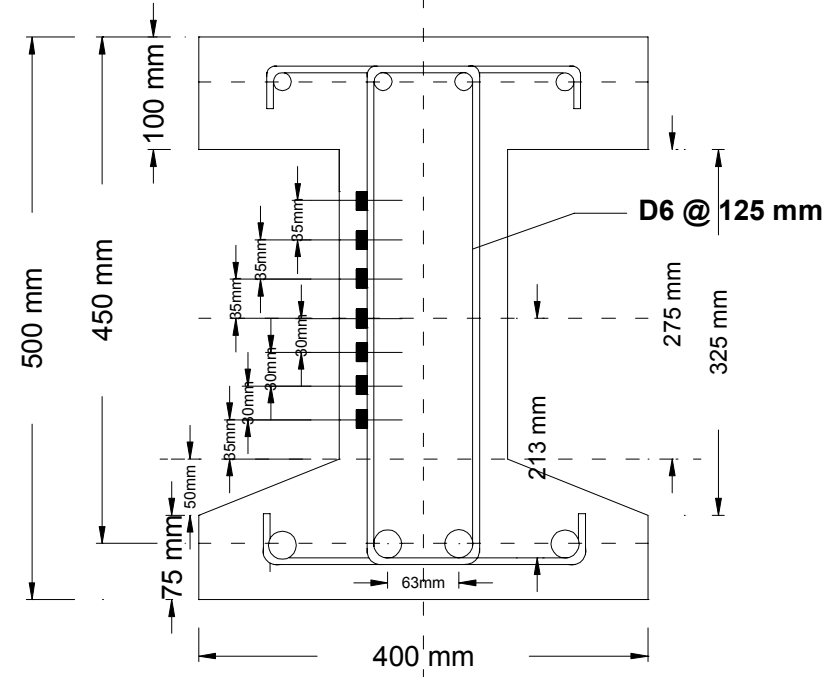

Type 1

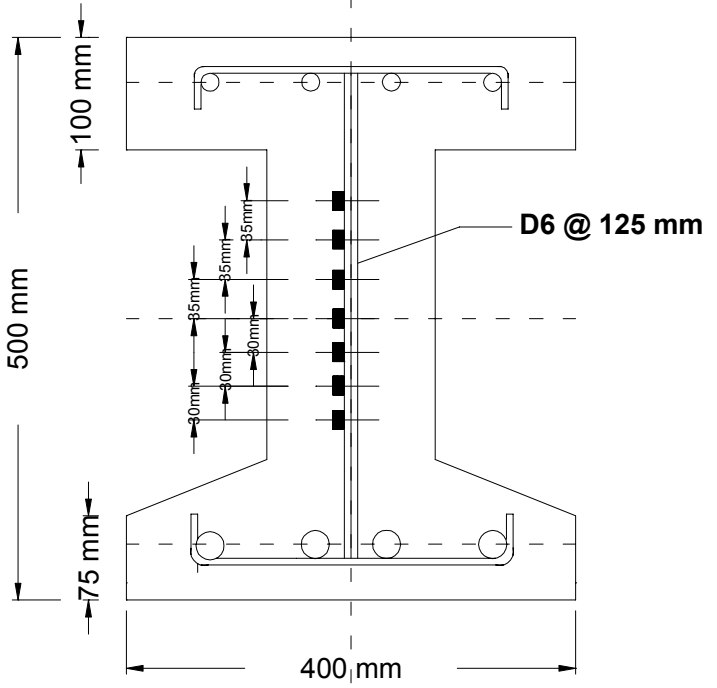

Type 2

Fig. 3 Details of stirrup strain gage locations.

at three locations in the shear span to measure the principal strains and their directions. A contact gage with an accuracy of $0.001 \mathrm{~mm}$ was used to measure the displacement in each direction of the contact chips. Linear voltage displacement transducers (LVDT) were installed to measure the mid-span deflection of the beam. A strain gage was attached to the top surface of the beam in the mid-span region to monitor the compressive strain in the concrete. A load-cell was placed on the loading beam to obtain the applied load. In the case of PRC beams, a load cell was also attached at the anchorage end of the prestressing tendon to monitor change of the applied prestressing force and to make sure that the beam was under uni-axial compressive force throughout the loading test.

\subsection{Loading and crack width measurements}

The test beams were subjected to four-point monotonic loading as shown in Fig. 4. The loading configuration consisted of simple supports and two point loads 300 $\mathrm{mm}$ apart at the mid-span. The ratio of shear span to effective depth (a/d) was 3.0 for all beams. A prestressing force of $375 \mathrm{kN}$ was introduced into all PRC beams, causing 3.0 MPa of compressive stress in the concrete. The sheath containing the prestressing tendon was filled with grout cement after prestressing. A hand-operated hydraulic jack was used to apply loading to the beam through the loading beam. A digital microscope with a resolution of $0.001 \mathrm{~mm}$ was used to capture digital images of cracks in the left span of the beam (Fig. 5(a)). These digital images were used to measure crack width. Crack widths perpendicular to the crack surface were obtained at three arbitrary points chosen close to the required points (that is, at strain gage locations) (Fig. 5(b)). The average of the three measurements was taken as the crack width at that location. Moreover, the propa-
Table 2 Properties of reinforcement.

\begin{tabular}{|c|c|c|c|c|}
\hline $\begin{array}{c}\text { Type of } \\
\text { bar }\end{array}$ & $\begin{array}{c}\Phi \\
(\mathrm{mm})\end{array}$ & Type $^{\dagger}$ & $\begin{array}{c}f_{y} \\
(\mathrm{MPa})\end{array}$ & $\begin{array}{c}\text { Es x } 10^{3} \\
(\mathrm{MPa})\end{array}$ \\
\hline Plain bar & $\varphi 6$ & \multirow{4}{*}{ SD $345^{*}$} & 353 & 167.7 \\
\hline \multirow{6}{*}{$\begin{array}{c}\text { Deformed } \\
\text { bar }\end{array}$} & D6 & & 438 & 180.4 \\
\hline & D10 & & 376 & \multirow{2}{*}{200.0} \\
\hline & D22 & & 397 & \\
\hline & D25 & \multirow{3}{*}{ USD $685 * \mathrm{~B}$} & 720 & \multirow{3}{*}{206.0} \\
\hline & D29 & & 735 & \\
\hline & D38 & & 726 & \\
\hline PC bar & $\varphi 26$ & $\begin{array}{c}\text { SBPR } \\
1080 * / 1230^{\S}\end{array}$ & 1205 & 200.0 \\
\hline
\end{tabular}

Japanese standard type bars

* Yield strength of bar in MPa

${ }^{\S}$ Ultimate strength of bar in Mpa

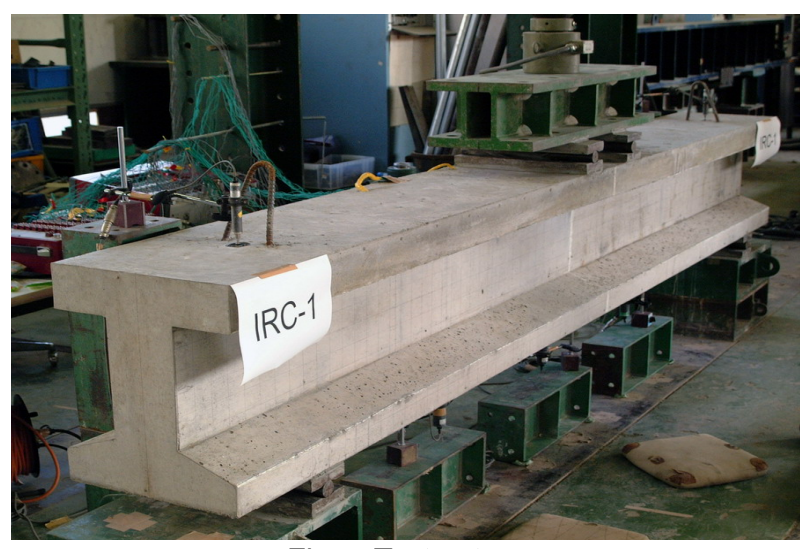

Fig. 4 Test setup.

gation and distribution of the cracks were carefully observed and marked at each loading increment until the failure of the beam. 


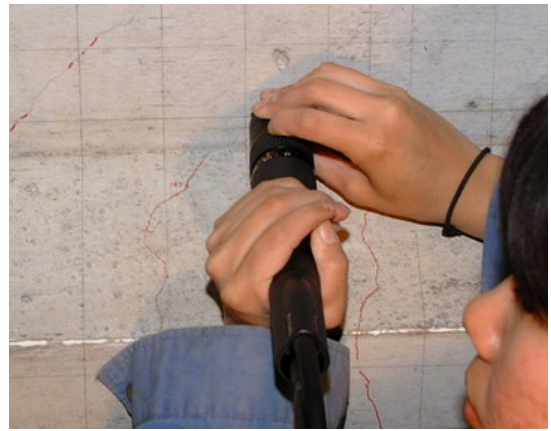

(a) Measuring crack width by using digital microscope

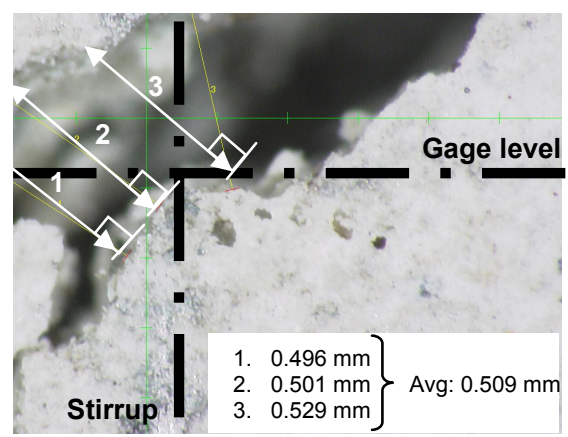

(b) Digital image of measured crack width

Fig. 5 Measuring shear crack width with digital microscope.

\section{Experimental results and discussion}

\subsection{Load-displacement characteristics}

As described above, an extensive experimental program was conducted to investigate the shear cracking behavior of I-shaped RC and PRC beams. The observed cracking loads and failure modes are summarized in Table 3. The compressive strength of the concrete at testing is summarized in Table 3. Figures 6(a) and 6(b) show the load versus mid-span deflection relationships for the RC and PRC beams, respectively. The load at the time of the first visible flexural crack in the mid-span

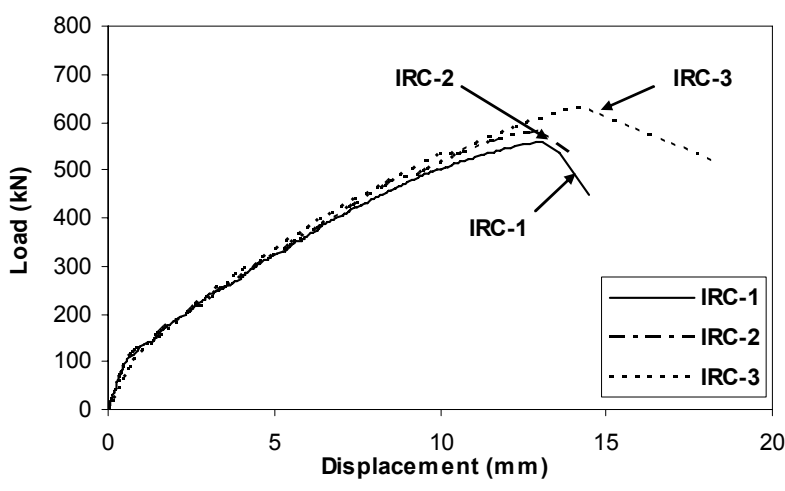

Fig. 6(a) Load versus mid-span deflection for RC beams.

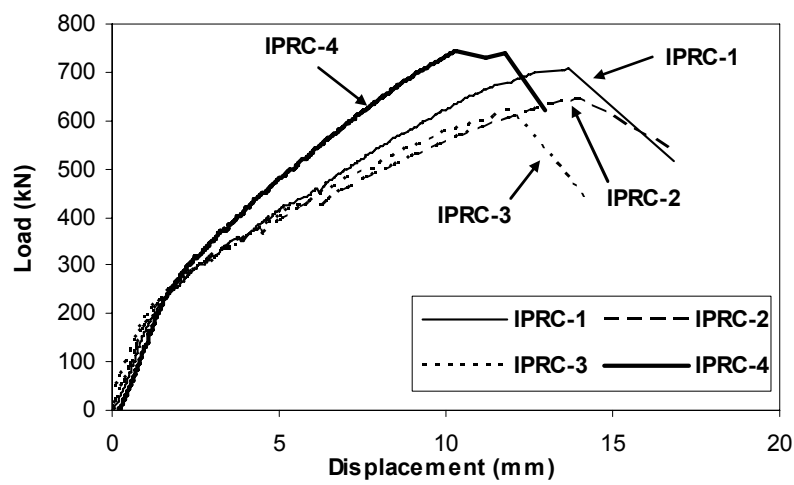

Fig. 6(b) Load versus mid-span deflection for PRC beams.

region ranged between $80 \mathrm{kN}$ and $90 \mathrm{kN}(15 \%$ of the ultimate capacity of each RC beam) for RC beams, while that for PRC beams was in the range of $165 \mathrm{kN}$ to $175 \mathrm{kN}(25 \%$ of the ultimate capacity of each PRC beam). This difference is mainly attributed to the prestressing force $(375 \mathrm{kN})$ applied to the PRC beams. With increasing load, the inclined shear cracks in the shear span region widened rapidly and propagated towards the loading points, while flexural crack widths in the mid-span region remained almost constant. The ultimate failure load was greater for the PRC beams than that for the RC beams (Table 3). In PRC beams, the ultimate load of the beam IPRC-4, with a large amount

Table 3 Failure loads and failure modes.

\begin{tabular}{|c|c|c|c|c|c|}
\hline Beam & $\begin{array}{c}f_{c}^{\prime} \\
(\mathrm{MPa})\end{array}$ & $\begin{array}{c}\text { Flexural } \\
\text { cracking } \\
\text { load }(\mathrm{kN})\end{array}$ & $\begin{array}{c}\text { Shear } \\
\text { cracking } \\
\text { load }(\mathrm{kN})\end{array}$ & $\begin{array}{l}\text { Ultimate } \\
\text { failure } \\
\text { load }(\mathrm{kN})\end{array}$ & Final failure mode \\
\hline IRC-1 & 40.3 & 90.0 & 220.4 & 559.7 & Shear compression $^{1}$ \\
\hline IRC-2 & 45.4 & 82.5 & 194.8 & 579.8 & Shear tension $^{2}$ \\
\hline IRC-3 & 44.0 & 85.0 & 220.1 & 629.0 & \multirow{3}{*}{ Shear compression } \\
\hline IPRC-1 & 41.8 & 165.0 & 290.9 & 706.8 & \\
\hline IPRC-2 & 49.3 & 175.0 & 310.2 & 644.0 & \\
\hline IPRC-3 & 45.0 & 165.0 & 290.2 & 622.7 & Shear tension \\
\hline IPRC-4 & 43.2 & 170.0 & 310.0 & 745.0 & Shear compression \\
\hline
\end{tabular}


of longitudinal reinforcement, was greater than that for the beam IPRC-1. The failure mode of all beams was shear failure with wide shear cracks in the shear span. Previous studies by Zararis (2001 and 2003) distinguished diagonal tension failure as "initial shear crack propagates abruptly or gradually toward the loading point crossing the compression zone with a wide shear crack in the shear span" and shear compression failure as "crushing of concrete in the compression zone at the top of the critical shear crack". The same definitions of diagonal tension failure and shear compression failure were followed in this study (see Table 3). Beams IRC-2 and IPRC-3 failed in diagonal tension failure mode with wide shear cracks in the shear span region, while all other beams failed in shear compression failure mode with crushing of the concrete at the upper flange near the left-hand loading point. Furthermore, at failure, all stirrups crossing the critical diagonal crack (D6 stirrups in the left span) were at yield and without yielding of the longitudinal reinforcement.

\subsection{Crack patterns and crack distribution}

Figure 7 shows the crack patterns and shear crack orientations for all beams. The inclination of shear cracks was determined by averaging the crack angles measured in the shear span region. The average angle of shear cracks to the beam axis in PRC beams was lower than that in $\mathrm{RC}$ beams. The average angle of shear cracks measured in $\mathrm{RC}$ beams was about 40 degrees while that in PRC beam varied between 30 and 35 degrees. This difference may be attributed to the axial stress component in the horizontal direction in PRC beams. This prestressing force caused greater reduction in the principal tensile stress in PRC beams than in RC beams, leading to the lower observed inclination of shear cracks in the PRC beams. Diagonal shear cracks in PRC beams intersect a larger number of stirrups than those in $\mathrm{RC}$ beams. Therefore, stirrups are more effective in transmitting shear force across cracks in PRC beams than in $\mathrm{RC}$ beams. It is noteworthy that prestressing force plays a more significant role in influencing the shear crack angle than the stirrup spacing in PRC beams. Table 4 shows the average measured shear crack spacing in the horizontal direction and the vertical direction for each beam. The crack spacings were measured when the load reached $70 \%$ of the ultimate load (that is, approximately the service load of the beam). The average spacing of these shear cracks in RC beams is larger than in PRC beams. This difference may be attributed to the compressive stress in the concrete resulting from the
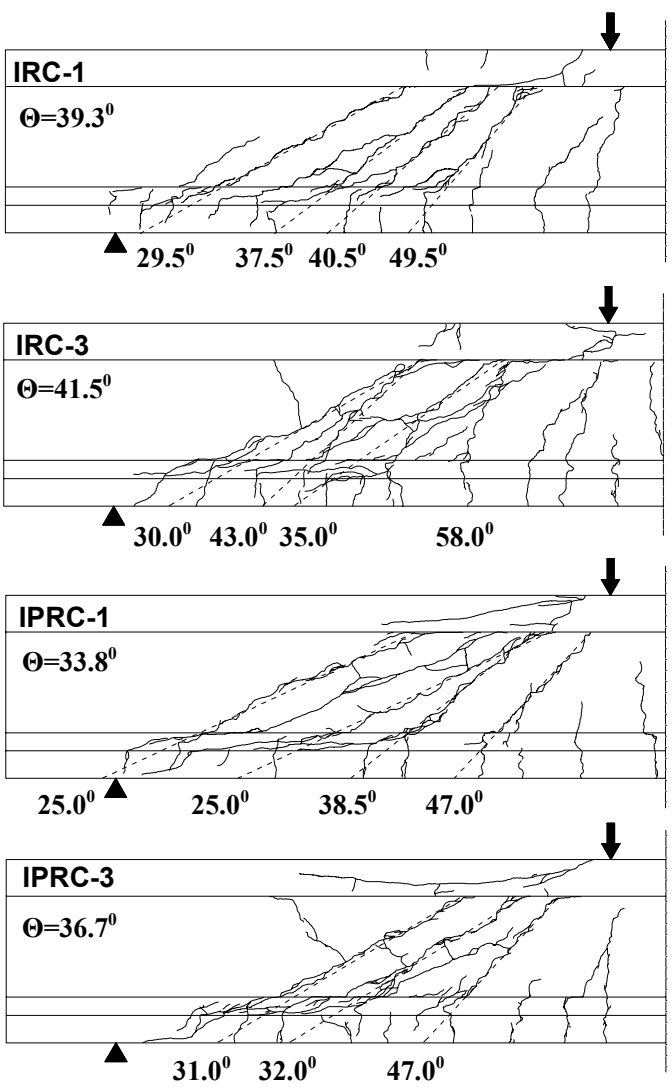

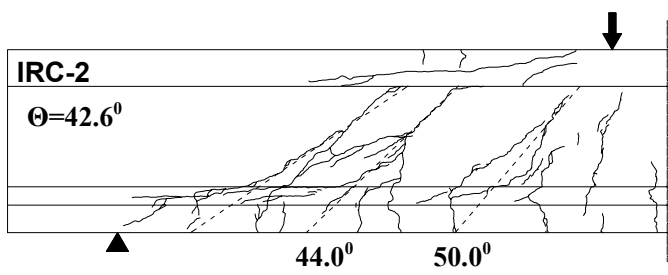

44.0 $50.0^{0}$

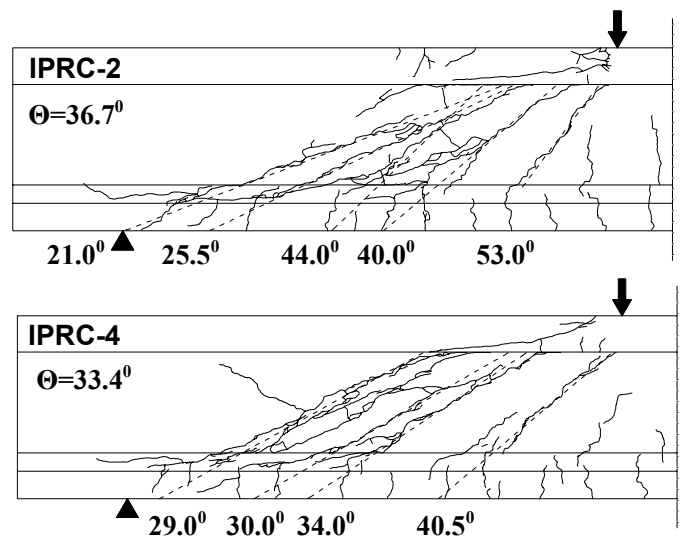

Fig. 7 Crack patterns of all beams in the left span. 
Table 4 Horizontal and vertical crack distribution.

\begin{tabular}{|c|c|c|c|c|}
\hline \multirow{2}{*}{ Beam } & \multicolumn{2}{|c|}{$\begin{array}{c}\text { Horizontal crack spacing } \\
\text { Smx, }(\mathrm{mm})\end{array}$} & \multicolumn{2}{c|}{$\begin{array}{c}\text { Vertical crack spacing } \\
\text { Smy, }(\mathrm{mm})\end{array}$} \\
\cline { 2 - 5 } & $\begin{array}{c}\text { Max. crack } \\
\text { spacing }\end{array}$ & $\begin{array}{c}\text { Avg. crack } \\
\text { spacing }\end{array}$ & $\begin{array}{c}\text { Max. crack } \\
\text { spacing }\end{array}$ & $\begin{array}{c}\text { Avg. crack } \\
\text { spacing }\end{array}$ \\
\hline IRC-1 & 248.25 & 167.00 & 138.00 & 108.29 \\
\hline IRC-2 & 344.60 & 241.46 & 250.00 & 250.00 \\
\hline IRC-3 & 254.20 & 208.93 & 167.50 & 158.75 \\
\hline IPRC-1 & 198.80 & 198.80 & 233.00 & 203.15 \\
\hline IPRC-2 & 235.60 & 200.95 & 155.50 & 127.75 \\
\hline IPRC-3 & 195.60 & 190.65 & 142.60 & 120.50 \\
\hline IPRC-4 & 290.50 & 287.15 & 166.40 & 157.30 \\
\hline
\end{tabular}

prestressing of the PRC beams.

\subsection{Effect of various parameters on shear crack width}

\subsubsection{Prestressing force}

The effect of prestressing force can be discussed by comparing the relationship between shear crack width and shear force, as shown in Figs. 8(b) and 8(c). Beam IRC-3 was designed with a prestressing tendon inside the concrete section without prestressing force, while beam IPRC-1 was given an effective prestressing force of $375 \mathrm{kN}$. The prestressing force in beam IPRC-1 was expected to increase the shear cracking load compared to the RC beam (see Fig. 8(c)). The load at which the

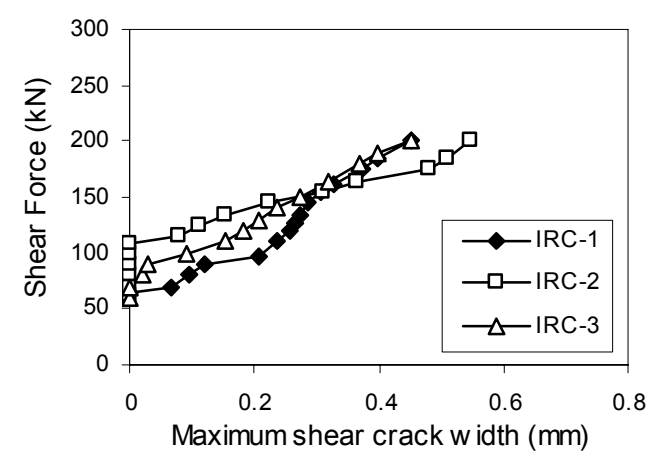

(a)

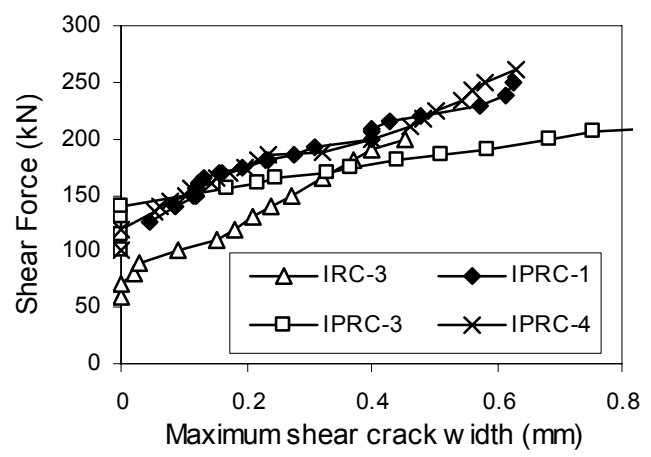

(c) shear crack width begins to increase or the stirrup strain starts to accumulate in the stirrup strain gages was considered as the shear cracking load (see Fig. 9(c)). The prestressing force in PRC beams also results in a reduction of maximum shear crack width compared to beam IRC-3 at the same shear force level. This implies that the prestressing force produces a significant increase in shear cracking load. After the occurrence of shear cracks, the increment in shear crack width with shear force is found not to be affected by prestressing force in PRC beams.

\subsubsection{Prestressing tendon as a tension rein- forcement}

The impact of providing a prestressing tendon at the centroid of the beam section was discussed by comparing the relationship between shear force and maximum crack width of beams IRC-1, IRC-3 $\left(\mathrm{P}_{\text {eff }}=0 \mathrm{kN}\right)$ and IPRC-1 $\left(\mathrm{P}_{\text {eff }}=375 \mathrm{kN}\right)$ as illustrated in Figs. 8(b) and 9(b). It can be seen that in beam IRC-3, in which a prestressing tendon was provided without prestressing force, the shear crack width was smaller at the same shear force level compared to beam IRC-1. The reason for this may be that the prestressing tendon at the centroid of the beam section may help to resist the externally applied load as a form of tension reinforcement by means of dowel action.

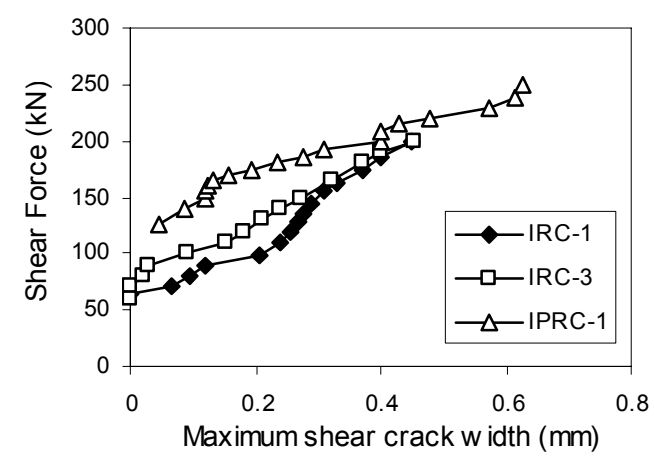

(b)

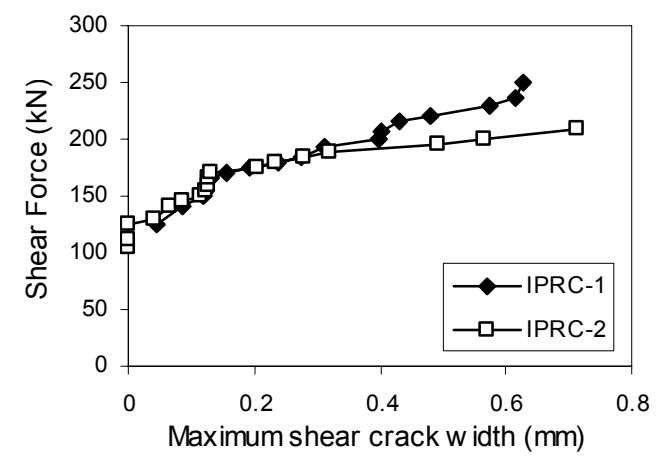

(d)

Fig. 8 Shear force versus maximum shear crack width. 


\subsubsection{Side concrete cover}

Figure 8(a) shows the relationship between shear force and maximum shear crack width. The side concrete cover of beams IRC-1 and IRC-2 were $25 \mathrm{~mm}$ and 69 $\mathrm{mm}$, respectively. It can be seen that the occurrence of shear cracks was delayed in beam IRC-2 compared to beam IRC-1. At the same shear force level, beam IRC-2 showed smaller shear crack width than beam IRC-1. Further, the maximum stirrup strain variation with shear force shows almost the same rate of stirrup strain increase in both beams (Fig. 9(a)). The relationship between average shear crack width and stirrup strain is shown in Fig. 10(a). It is very clear that a wider side concrete cover tended to increase the shear crack width at the same stirrup strain level. However, the shear crack pattern in beam IRC-2 shows relatively wide spacings of shear cracks compared to the other RC beams (Fig. 7). Further investigation is necessary to verify the effect of side concrete cover on shear crack width.

\subsubsection{Type of stirrup}

It can be observed from Fig. 8(c) that, for a particular shear force, beam IPRC-3 with plain stirrups (round bars) showed a larger shear crack width compared to beam IPRC-1 with deformed stirrups. More interestingly, the relationship between shear crack width and stirrup strain for plain stirrups was found to be nonlinear (a polynomial curve), as opposed to a linear relationship in the case of deformed stirrups (Fig. 10(d)). For the same stirrup strain, shear crack width tended to be larger in the beam with plain stirrups. This may be because a plain stirrup undergoes more slip than a deformed stirrup because of its inferior bonding characteristics. Stirrup slip is considered to be a major factor in the opening of shear cracks. The width of shear cracks at a given stirrup strain level will be greater for the plain stirrups compared with the deformed stirrups. Due to the better bonding with deformed bar strain of deformed bar shows smaller at a distance from crack intersection. As a result, overall strain with a deformed bar is smaller and causes smaller shear crack width. Due to inferior bonding between plain stirrups and concrete, stirrup strain in plain stirrups shows uniform and smaller stirrup strain distribution compared to deformed type stirrups. The effect of bond condition of stirrups in PRC beams on shear cracking behavior is similar to that observed for RC members in a previous study by Hassan et al. (1991).

\subsubsection{Amount of longitudinal reinforcement}

To examine the influence of longitudinal reinforcement ratio on shear cracking behavior in PRC beams, the re-

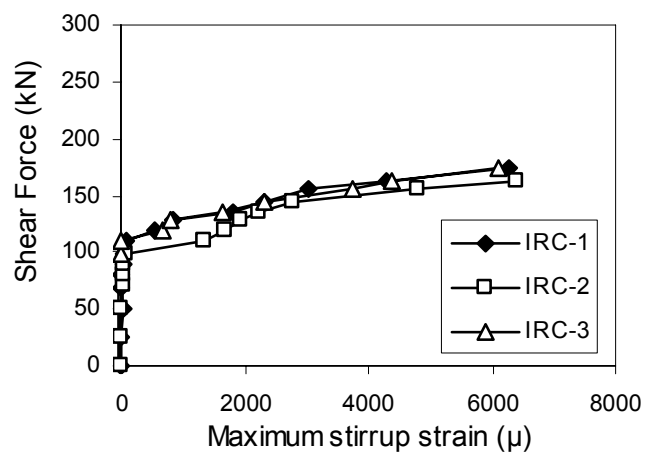

(a)

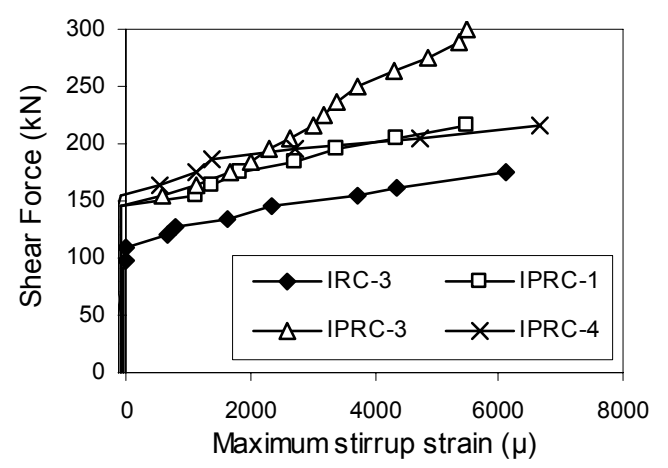

(c)

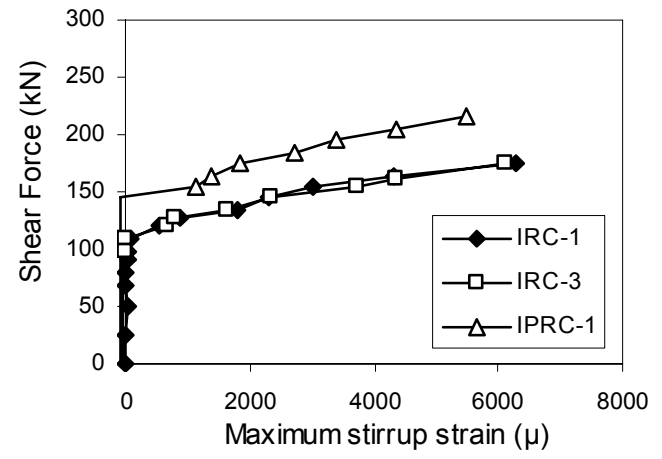

(b)

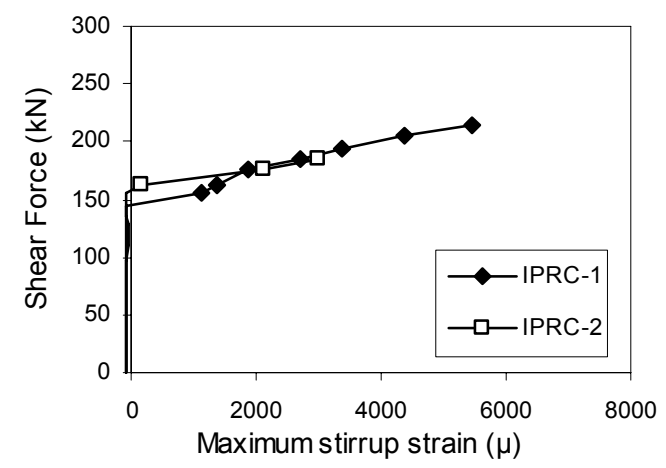

(d)

Fig. 9 Shear force versus maximum stirrup strain. 


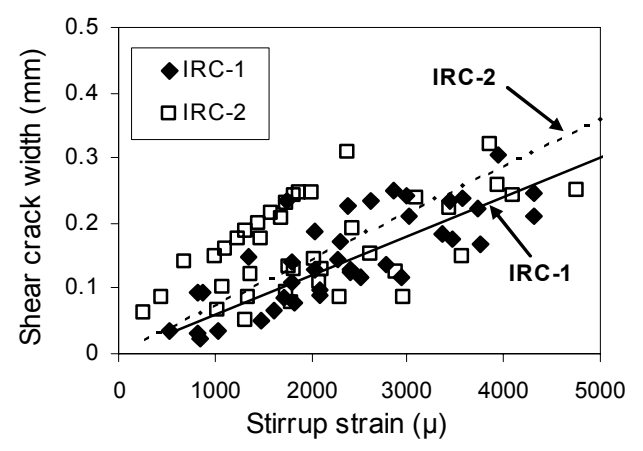

(a)

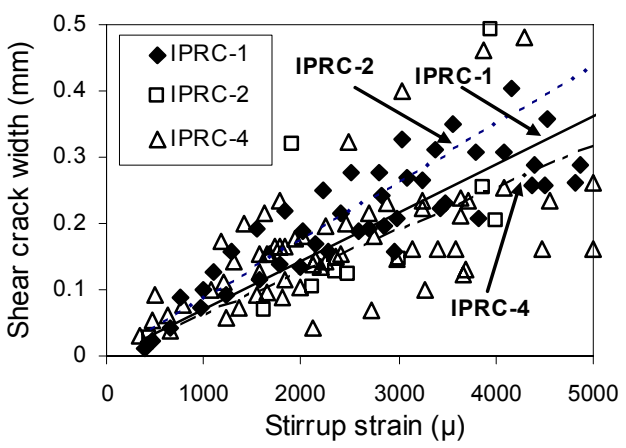

(c)

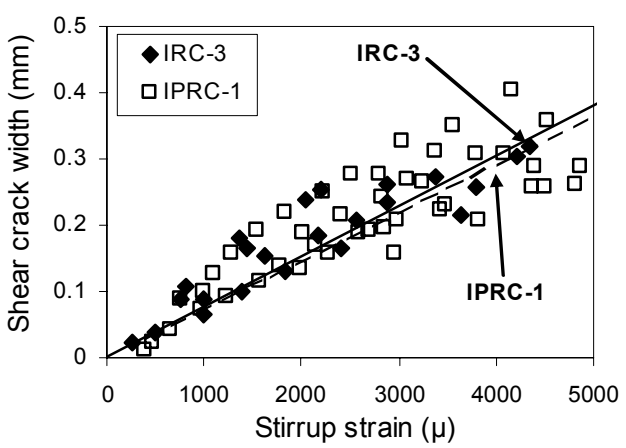

(b)

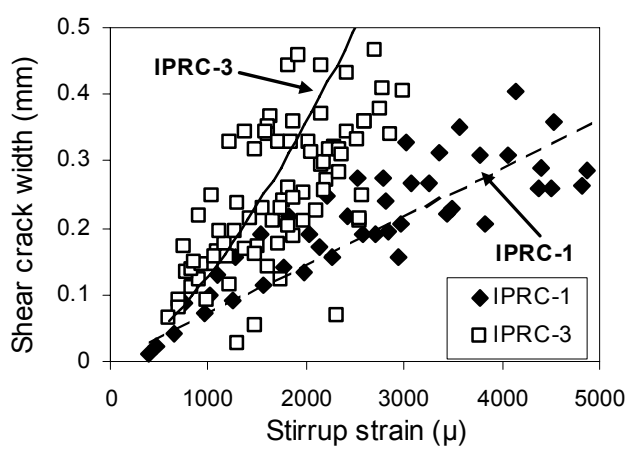

(d)

Fig. 10 Shear crack width versus stirrup strain.

inforcement ratio $\left(\rho_{s}=A_{s} / b d\right)$ was increased from $1.13 \%$ (beam IPRC-1) to $1.98 \%$ (beam IPRC-4). Beam IPRC-4 has $75 \%$ more longitudinal reinforcement than beam IPRC-1. The rate of increase in shear crack width with shear force was found to be unaffected by the amount of longitudinal reinforcement (Fig. 8(c)). Further, the rate of stirrup strain increase was found to be the same in both beams IPRC-1 and IPRC-4 (Fig. 9(c)). It seems that the amount of longitudinal reinforcement has an insignificant effect on the shear cracking behavior of PRC beams.

\subsubsection{Stirrup ratio}

To investigate the effect of the stirrup ratio on shear crack width in beams IPRC-1 and IPRC-2, the stirrup ratio was changed from $0.338 \%$ (stirrup spacing, $s=$ $125 \mathrm{~mm})$ to $0.188 \%(s=225 \mathrm{~mm})$, respectively, as shown in Figs. 1 and 2. Figure 8(d) shows the relationship between shear crack width and shear force. This implies that shear cracking load is not affected by the stirrup ratio in PRC beams. Further, the maximum shear crack width seems to be independent of the stirrup ratio, particularly at lower shear forces, in PRC beams. This insignificant effect on shear crack width is attributed to the high prestressing force (e.g. $\mathrm{P}_{\text {eff }}=375 \mathrm{kN}$ ) in PRC beams. However, in RC beams as well as PRC beams with low prestressing force $\left(\mathrm{P}_{\mathrm{eff}} \leq 150 \mathrm{kN}\right)$, the stirrup ratio had a significant influence on maximum shear crack width (Hassan et al., 1991, De Silva, 2005). Thus there is a need to further investigate the effect of stirrup ratio on maximum shear crack width in the case of PRC beams.

\subsection{Distribution of stirrup strain over beam height}

Figures 11(a) to 11(d) show the distribution of stirrup strain (in the stirrup placed at a distance of $500 \mathrm{~mm}$ from the loading point) at different loading stages, over the beam height for beams IRC-1, IPRC-1, IPRC-2 and IPRC-3, respectively. A shear crack intersecting a stirrup causes a sudden increase in strain measured by the stirrup strain gage attached close to the location of the crack intersection. In the case of beam IPRC-1, shear cracks appeared with a lower angle to the member axis compared with beam IRC-1 (Fig. 7). As a result, there is no large increase in stirrup strain in the upper strain gages on the stirrups of this beam (Fig. 11(b)). However, a different stirrup strain distribution was seen in beam IPRC-3, which had plain (round bar) stirrups (Fig. 11(d)). Small stirrup strains were observed due to inferior bonding characteristics between the plain stirrup and the concrete. This is because slip occurs when a shear crack intersects the stirrup. 


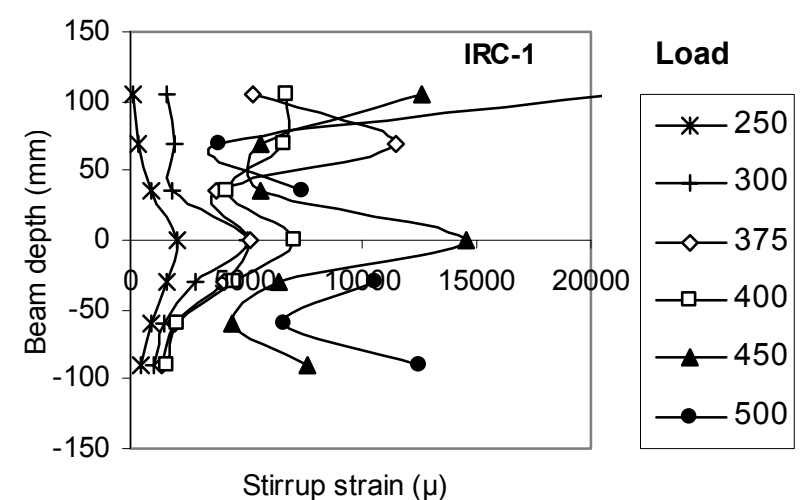

(a) IRC-1 ( $s=125 \mathrm{~mm})$

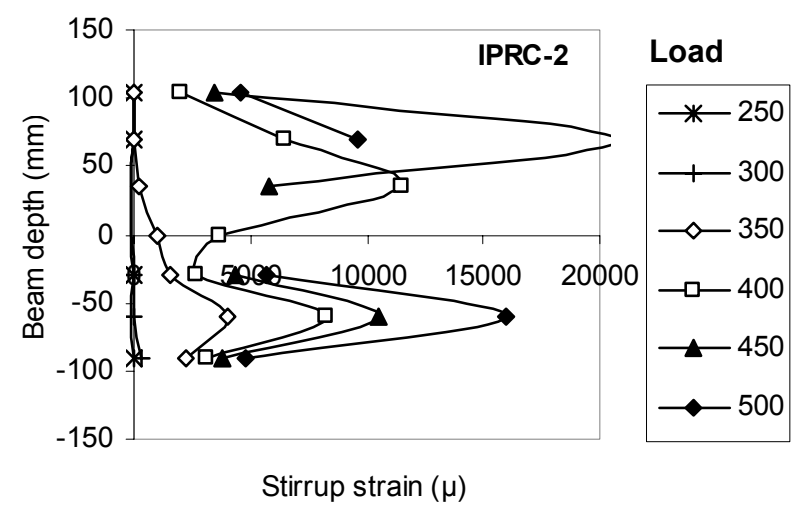

(c) IPRC-2 (s=225 mm, $\left.P_{e}=375 \mathrm{kN}\right)$

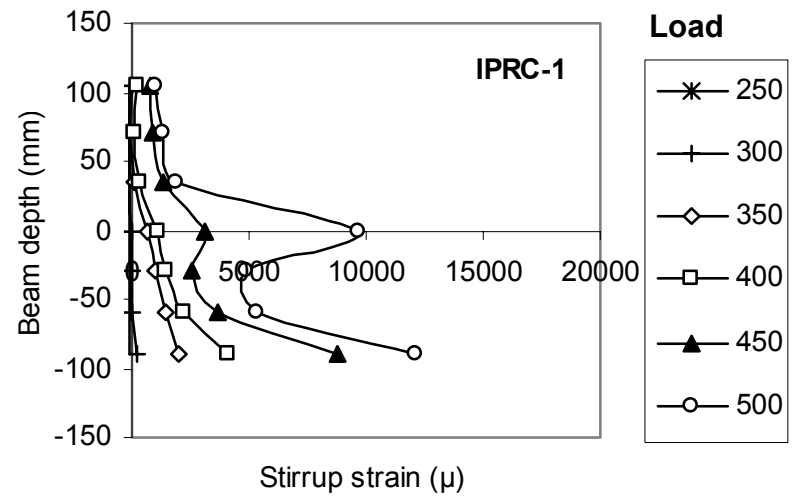

(b) IPRC-1 ( $s=125 \mathrm{~mm}, \mathrm{P}_{\mathrm{e}}=375 \mathrm{kN}$ )

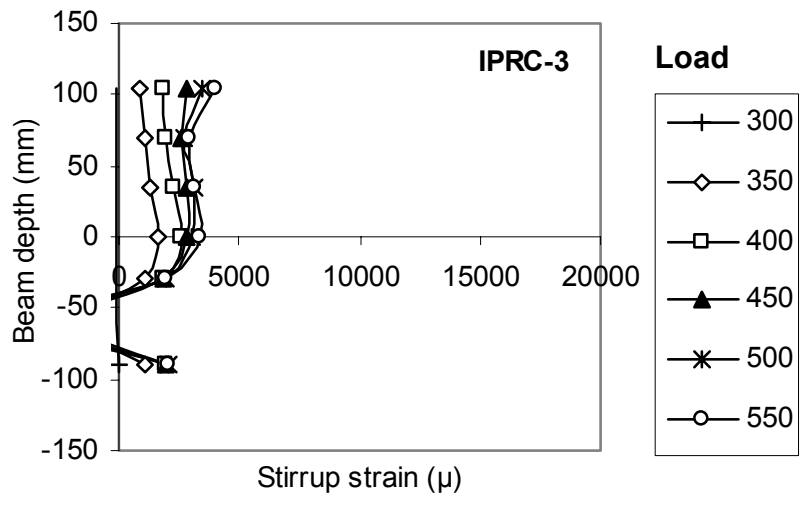

(d) IPRC-3 ( $s=125 \mathrm{~mm}$ (plain stirrups), $\left.P_{e}=375 \mathrm{kN}\right)$

Fig. 11 Stirrup strain distribution over the beam depth.

\subsection{Distribution of shear crack width over the beam height}

Figures 12(a) to 12(d) show the variation of maximum shear crack width over the beam height. Shear crack widths were distributed uniformly over the beam depth in both RC and PRC beams at each load increment. The average load at which the stirrups yield was between $300 \mathrm{kN}$ and $400 \mathrm{kN}$ for both RC and PRC beams. The maximum shear crack width over the beam depth in RC beams was observed to be greater than $0.3 \mathrm{~mm}$ ((Fig. 12(a)). However, in PRC beams, it was $0.2 \mathrm{~mm}$, a much lower value. It is clear that the prestressing force in PRC beams significantly controls shear crack width up to the service load. Beam IPRC-2 was designed to have larger stirrup spacing than beam IPRC-1. Therefore, with increasing load, a sudden increase in shear crack widths was observed in beam IPRC-2 (Fig. 12(c)). This is due to the wider stirrup spacing, resulting in a smaller restraining effect against the growth of shear cracks in the web. In addition, beam IPRC-3, which had a plain (round bar) stirrup, exhibited a sudden increase in shear crack width as beam IPRC-2 when the load increased (Fig. 12(d)). This results from the inferior bonding be- tween web reinforcement and concrete, which leads to greater shear displacement along the plain stirrups.

\section{Proposed design methodology for shear crack width}

\subsection{Evaluation of existing equations}

The test results presented in the previous studies (Adebar and Leeuwen 1999; De Silva 2005), and in the present study have shown that strains of stirrups are the most important factor affecting the shear crack width of $\mathrm{RC}$ and PRC beams. Although the shear crack widths can be related to the strain of stirrup, there is a larger variation of shear crack widths at the same stirrup strain level. For this reason, no general conclusion can be made on the exact relationship between shear crack width and stirrup strain. Some researchers (Fukuyama et al., 2000; Shinomiya and Watanabe 2002) suggested a simple linear relationship, while some other researchers (Hassan et al. 1991; Piyamahant 2002) proposed a second order polynomial relationship. Table 5 shows a summary of available formulae for predicting shear crack width for RC beams. It should be noted that the 


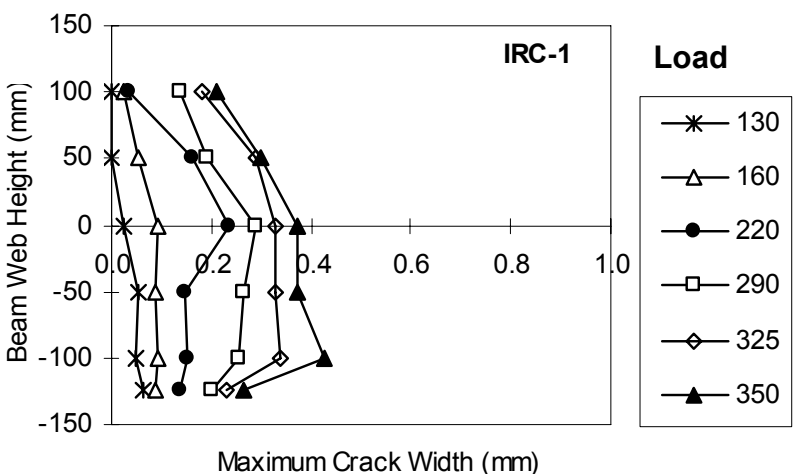

(a) IRC-1 (s=125 mm)

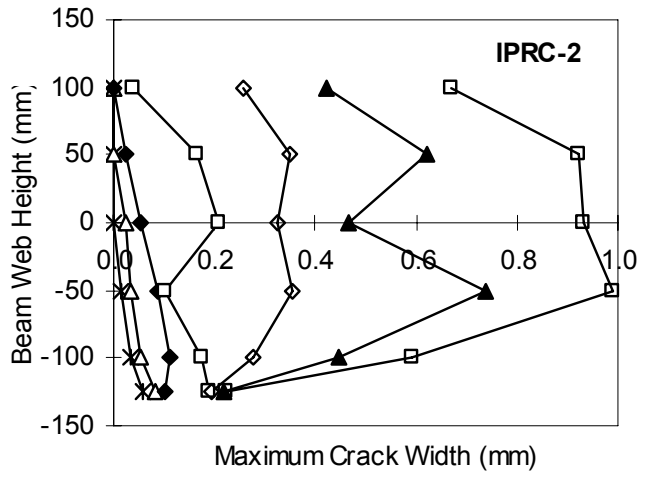

(c) IPRC-2 (s =225 mm, $P_{e}=375 \mathrm{kN}$ )

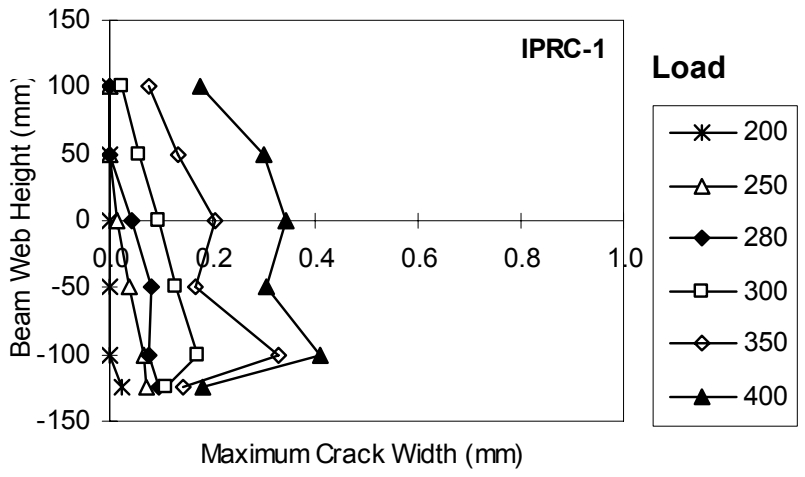

(b) IPRC-1 (s=125 mm, $\left.P_{e}=375 \mathrm{kN}\right)$

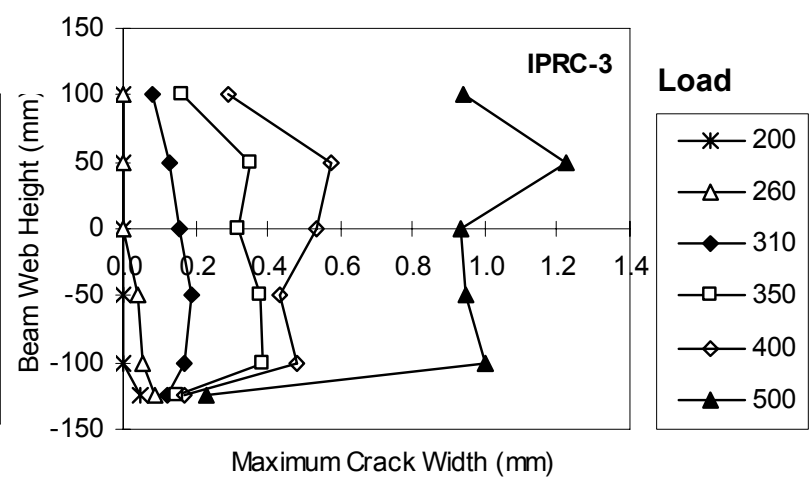

(d) IPRC-3 ( $s=125 \mathrm{~mm}$ (plain stirrups), $P_{e}=375 \mathrm{kN}$ )

Fig. 12 Maximum shear crack width over the beam depth.

formulae are empirically obtained from the fitting of experimental data of shear crack width and stirrup strain. Although some prediction formulae for estimating shear crack width have been proposed by some investigators, most of them are based on semi-empirical methods. Moreover, such prediction formulations were originally developed for RC members, hence parameters concerning the effect of prestress are not considered. Therefore, the applicability of existing shear crack width prediction formulae in PRC members needs to be carefully investigated.

To verify the applicability of available formulae for predicting shear crack width in PRC members, the shear crack widths calculated by various predication equations are compared with experimentally measured values as illustrated in Figs. 13(a) and 13(b) for beams IRC-1 and IPRC-1, respectively. It was clear that the shear crack widths predicted by all equations seem to be overestimated, despite the fact that the predicted crack widths are average crack widths. This may be attributed to the fact that the parameters related to prestressing force, the presence of prestressing tendon in PRC beams and the crack control characteristics of both longitudinal reinforcement and transverse reinforcement, can affect the shear crack widths. However, these effects are not taken into account in any existing prediction formulae.

\subsection{Derivation of shear crack width formula}

The proposed equation to calculate the shear crack width of RC and PRC members was developed based on the assumption that there is an almost linear relationship between shear crack width $(w)$ and stirrup strain $\left(\varepsilon_{w}\right)$. As discussed in the preceding sections (3.3.1 to 3.3.6), the factors affecting the shear crack width and stirrup strain relationship are stirrup spacings, prestressing force, presence of prestressing tendon at the centroid of the section, etc. By neglecting the effect of tension stiffening, the average shear crack width is equal to the product of the average spacing of shear cracks, $s_{m \theta}$, and the stirrup strain, $\varepsilon_{w}$.

$$
w_{k}=s_{m \theta} \varepsilon_{w}
$$

\subsubsection{Shear crack spacing model}

The concept of this approach is based on the smeared crack model, in which the actual complex crack pattern is idealized as a series of parallel cracks occurring at an angle of $\theta$ to the longitudinal axis of the member (Fig. 14). This means that shear cracks are uniformly distrib- 
Table 5 Summary of formulae for average shear crack width.

\begin{tabular}{|c|c|c|}
\hline Researchers & Proposed equations & Description of parameters \\
\hline $\begin{array}{l}\text { CEB-FIP Model } \\
\text { Code (1978) }\end{array}$ & $\begin{aligned} \mathrm{W}_{\mathrm{k}} & =1.7 \mathrm{k}_{\mathrm{w}} \mathrm{W}_{\mathrm{m}} \\
w_{m} & =S_{r m} \varepsilon_{s m} \\
s_{r m} & =2\left[c+\frac{s}{10}\right]+k_{1} k_{2} \frac{\phi}{\rho_{r}} \leq \frac{d-x}{\sin \alpha}\end{aligned}$ & $\begin{array}{l}c \text { is the concrete cover, } s \text { is the spac- } \\
\text { ing of the reinforcement bars } \\
(s \leq 15 \varphi), k_{l} \text { for deformed bars } 0.4 \text { and } \\
0.8 \text { for plain bars, } k_{2}=0.25, \varphi \text { is bar } \\
\text { diameter, } \rho r \text { is } A s / A c, e f, \varepsilon_{s m} \text { is the } \\
\text { stirrup strain }\end{array}$ \\
\hline $\begin{array}{l}\text { Hassan et al., } \\
\text { (1991) }\end{array}$ & $\begin{array}{l}w_{m}=\left[\frac{\phi}{1000}\right] S \frac{k_{1} k_{2}}{k_{f c} k_{p}} \\
k_{p}=\left[\frac{\rho_{w}}{0.004}\right]^{1.3} ; k_{f c}=\left[\frac{f_{c}^{\prime}}{19.6}\right]^{2 / 3}\end{array}$ & $\begin{array}{l}\text { For plain bar } \\
K_{1}=2.4 \\
\mathrm{~S}=4 \times 10^{3} \varepsilon_{\mathrm{w}}+2 \times 10^{6}\left(\varepsilon_{\mathrm{w}}\right)^{2} \\
\text { For deformed bar } \\
K_{1}=2.0 \\
\mathrm{~S}=8 \times 10^{3} \varepsilon_{\mathrm{w}}+2 \times 10^{6}\left(\varepsilon_{\mathrm{w}}\right)^{2} \\
K_{2}: 1.2 \text { for vertical stirrups } \\
\quad: 1.0 \text { for inclined stirrups } \\
f_{c} \text { ' is the compressive strength of } \\
\text { concrete }\end{array}$ \\
\hline $\begin{array}{l}\text { Fukuyama et al., } \\
(2000)\end{array}$ & $w_{s c r}=0.9 D \frac{{ }_{w} \varepsilon_{s}}{\sqrt{2}}$ & $\begin{array}{l}D: \text { overall depth of the section }(\mathrm{mm}) \\
{ }_{\mathrm{w}} \boldsymbol{\varepsilon}_{\mathrm{s}}=\text { stirrup strain }\end{array}$ \\
\hline $\begin{array}{l}\text { Shinomiya et al., } \\
\text { (2002) }\end{array}$ & $\begin{aligned} w_{a v} & =l_{a v} * \varepsilon_{t, a v} \\
l_{a v} & =2\left[\frac{c_{S}+c_{b}}{2}+\frac{s}{10}\right]+0.1 \frac{\phi}{\rho_{e}}\end{aligned}$ & $\begin{array}{l}\rho_{\mathrm{e}}=\mathrm{A}_{\mathrm{w}}\left[\left(2 \mathrm{C}_{\mathrm{b}}+\varphi\right) / \mathrm{b}\right], b \text { is beam width, } \\
c_{b}=\left(s_{y}-\varphi\right) / 2 ; c \text { is the side concrete } \\
\text { cover, } s_{y} \text { is the stirrup spacing, } s \text { is } \\
\text { the distance between stirrup legs }\end{array}$ \\
\hline $\begin{array}{l}\text { Piyamahant } \\
\text { (2002) }\end{array}$ & $w_{a v}=\frac{2 d_{v} s}{\left(f_{c}^{\prime} / 20\right)^{2 / 3}} ; s=\varepsilon_{w}\left(6+3500 \varepsilon_{w}\right)$ & $\begin{array}{l}f c^{\prime} \text { is the compressive strength of } \\
\text { concrete, } d v=\text { diameter of stirrup, } \mathrm{s}= \\
\text { normalized slip, } \varepsilon_{w}=\text { stirrup strain }\end{array}$ \\
\hline
\end{tabular}

uted with constant crack angle $(\theta)$ and crack spacing $\left(s_{m \theta}\right)$, as shown in Fig. 15(a). The spacing of the shear cracks, $s_{m \theta}$, depends on the crack control characteristics of both the longitudinal and transverse reinforcement, as shown in Figs. 15(b) and 15(c), respectively. The CEBFIP Model Code (1990) provides an expression for an average crack spacing in two orthogonal directions, as shown in Eq. (2).

$$
s_{m \theta}=\left\{\frac{1}{\frac{\sin \theta}{s_{m x}}+\frac{\cos \theta}{s_{m y}}}\right\}
$$

where $s_{m x}$ is the average horizontal crack spacing (that would result if the member is subjected to axial tension), and $s_{m y}$ is the average vertical crack spacing (that would result if the member is subjected to transverse tension). The idea of these crack spacings is estimated from the crack spacing expression written in the CEB-FIP Model Code (1978):

$$
s_{m}=2\left[c+\frac{s}{10}\right]+k_{1} k_{2} \frac{d_{b}}{\rho}
$$

The crack spacing expression in the CEB-FIP Model Code (1978) was intended to calculate crack spacing on the member surface. Further, this expression considers crack spacing in the shear span region of the member and the distribution of cracks inclined to the reinforcements. To account for the fact that the shear crack spacing increases as the distance between the member surface and the reinforcement increases, the maximum distance away from the reinforcement $\left(c_{x}\right.$ and $\left.c_{y}\right)$ instead of side concrete cover, $c$, was used. Therefore Eq. (3) was modified as the following equations to calculate the horizontal crack spacing $\left(s_{m x}\right)$ and the vertical crack spacing $\left(s_{m y}\right)$.

$$
\begin{aligned}
& s_{m x}=2 \alpha_{1}\left[c_{x}+\frac{s_{x}}{10}\right]+k_{1} k_{2} \alpha_{1} \frac{d_{b x}}{\rho_{x}} \\
& s_{m y}=2 \beta_{1}\left[c_{y}+\frac{s_{y}}{10}\right]+k_{1} k_{2} \beta_{1} \frac{d_{b v}}{\rho_{v}}
\end{aligned}
$$

where

$c_{x}$ : distance from the horizontal centre line of the section to longitudinal reinforcements (see Fig. 16)

$c_{y}$ : distance from the centre line of the section to the inner edge of vertical reinforcement (see Fig. 16)

$s_{x}$ : longitudinal reinforcement spacing

$s_{y}$ : web reinforcement spacing

$k_{l}$ : coefficient representing the bond characteristics of the bars $(0.4$ for deformed bars and 0.8 for plain bars) $k_{2}$ : coefficient representing the influence of the form of the stress diagram ( 0.25 for pure tension)

$d_{b x}$ : diameter of longitudinal reinforcement

$d_{b v}$ : diameter of web reinforcement

$\rho x$ : amount of longitudinal reinforcement; 

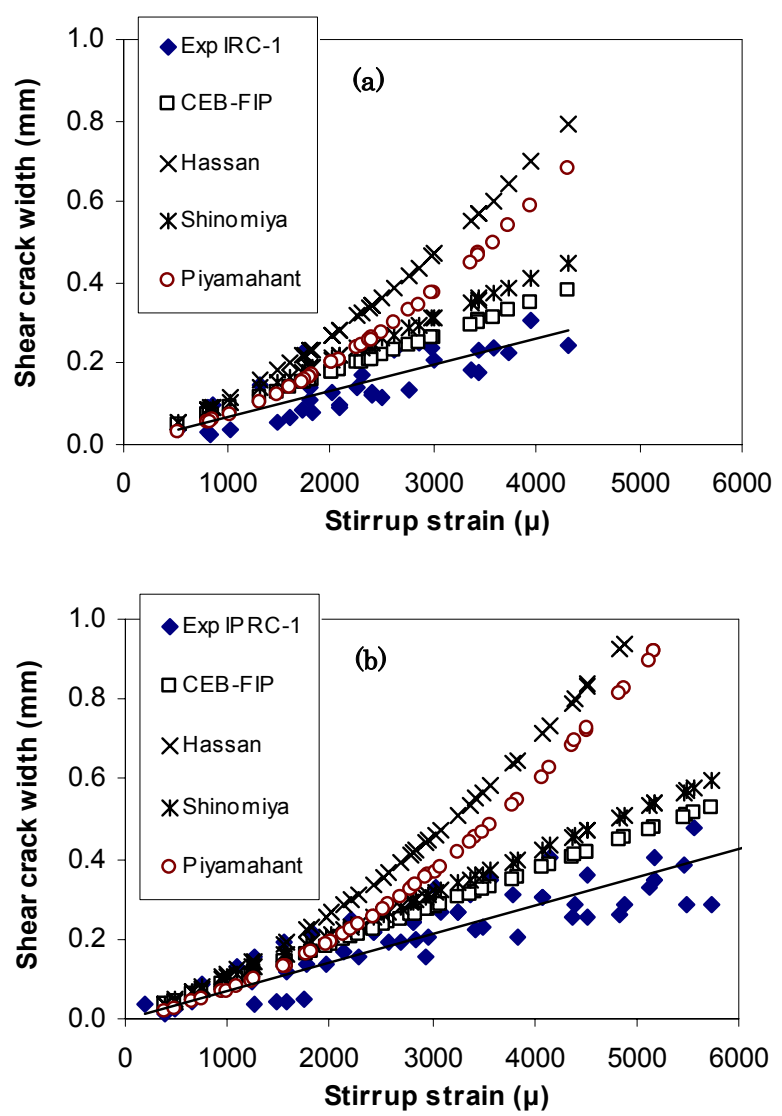

Fig. 13 Accuracy of available prediction formulae for shear crack width.

$\rho_{x}=\frac{A_{x}+A_{p x}}{A_{c, e f}}$

$A_{c, e f}:$ effective concrete area $\left[2.5 \mathrm{x}\left(h-d_{e}\right) \mathrm{x}\right.$ width of section $\left(b_{x}\right)$ ] (CEB-FIP Model Code (1990))

$h$ : overall height of the section

$d_{e}$ : effective depth based on total longitudinal steel including prestressing tendon

$b_{x}$ : width of the hatch sections (see Fig. 16) along the effective height (i.e., $2.5 \mathrm{x}\left(h-d_{e}\right)$ )

$A_{x}$ : total area of longitudinal reinforcement $A_{p x}:$ total area of prestressing steel
$A_{c, e f}:$ effective concrete area

$\rho_{v}$ : amount of web reinforcement; $\rho_{v}=\frac{A_{v}}{b_{w} s_{y}}$

$A_{v}$ : total area of web reinforcement

$b_{w}$ : web width in mm

In addition, the proposed crack spacing model takes into account the presence of prestressing tendons $\left(A_{p x}\right)$ in PRC beams. The total area of longitudinal reinforcements is distributed in the effective concrete area $\left(A_{c, e f}\right)$ as shown in Fig. 16. The effective concrete area $\left(A_{c, e f}\right)$ is calculated based on the steel centroid (that can be obtained using $A_{p x}$ and $A_{x}$ ). In the case of different shapes of cross sections (e.g. I-shaped), $A_{c, e f}$ is calculated based on the width of the flange and the width of the web along the effective height. The correlation factors, $\alpha_{1}$ and $\beta_{1}$, are determined from the regression analysis of experimental values. It was found that $\alpha_{1}$ and $\beta_{1}$ are equal to 0.36 .

\subsubsection{Verification of shear crack spacing model}

Table 6 shows a comparison of the calculated shear crack spacing values and the experimental results. The calculated shear crack spacing values show reasonably good agreement with the experimental values. However, beam IRC-2 shows relatively wide spacings of cracks (Fig. 7) compared to the other RC beams. Therefore it seems that the proposed crack spacing model overly underestimates the crack spacing in beam IRC-2.

\subsection{Design methodology for shear crack width}

A design methodology for average shear crack width is proposed in Eq. (5). To incorporate the effect of shear crack angle, a shear crack spacing parameter $\left(s_{m \theta}\right)$ is included. The shear crack spacing, $s_{m \theta}$, can be determined using the horizontal crack spacing $s_{m x}$, and vertical crack spacing, $s_{m y}$, from the provision suggested in the CEB-FIP Model Code 1978, as discussed in the preceding section. The average shear crack width, $w_{k}$, can be expressed as follows;

$$
w_{k}=k_{w} s_{m \theta} \varepsilon_{w}
$$

where
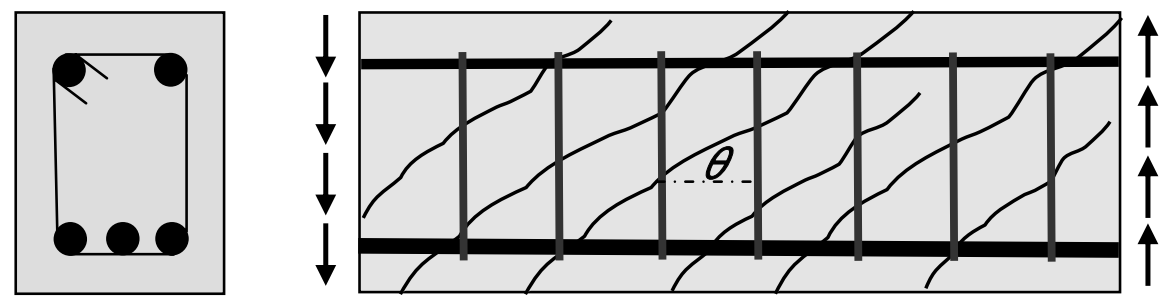

Fig. 14 Actual complex shear crack distribution. 
$w_{k}$ : average shear crack width perpendicular to the crack surface

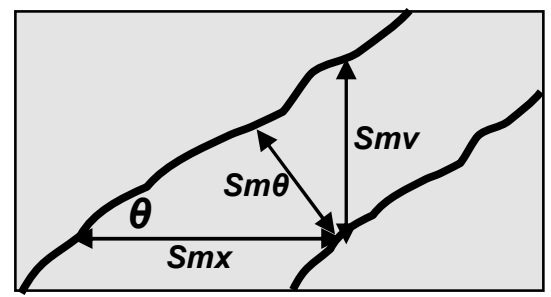

(a) Shear crack spacing

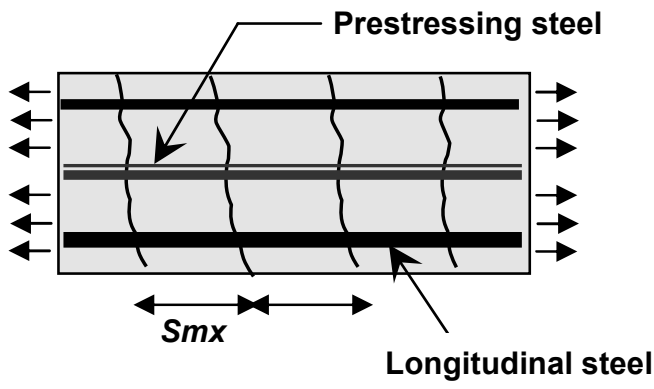

(b) Vertical cracks due to axial tension

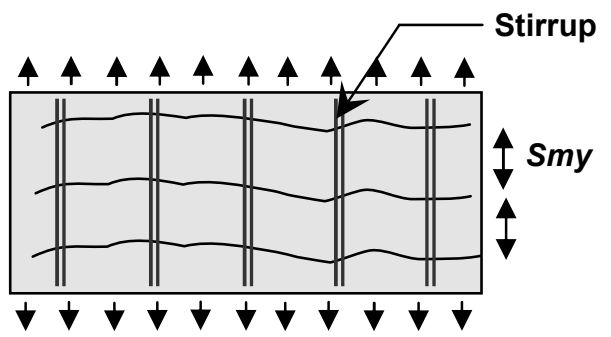

(c) Horizontal cracks due to transverse tension

Fig. 15 Idealized shear crack distribution.

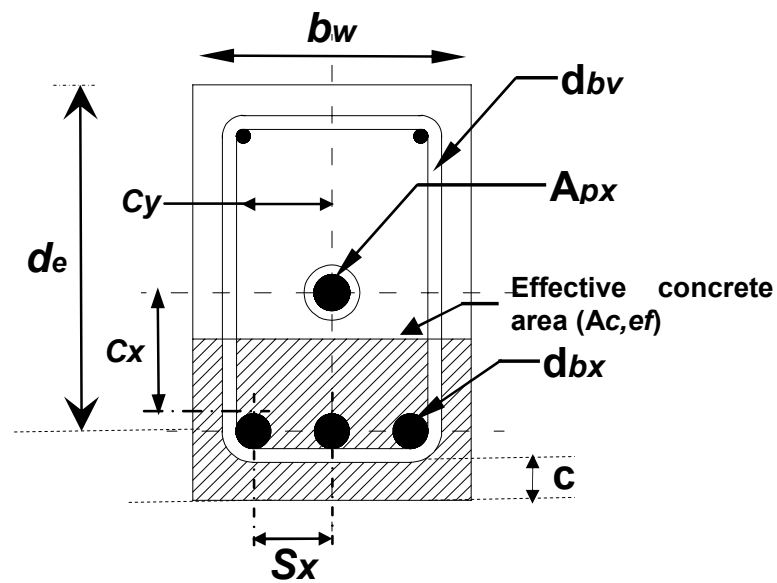

(a) Rectangular shaped beam $k_{w}$ : coefficient for effect of web reinforcement angle, (1.2 for vertical stirrups; 0.8 for stirrup with $45^{\circ}$ to $60^{\circ}$ angle to member axis)

$s_{m \theta}$ : average shear crack spacing

$\varepsilon_{w}$ : strain in web reinforcement (equation stipulated in JSCE (2002) code based on truss theory)

The proposed shear crack spacing model and shear crack width formula are compared with experimental data measured in this study. The accuracy of the proposed equation for calculating the shear crack width in beam IRC-1 and beam IPRC-1 are illustrated in Figs. 17(a) and 17(b), respectively. The average shear crack width is calculated using Eq. (5). In this calculation, stirrup strain is the measured stirrup strain at the same location of the measured crack width. The calculated shear crack widths show good correlation with the measured shear crack widths. In addition, it can be seen from Table 7 that the scatter, characterized by the standard deviation $(\sigma)$ and the correlation of variance $(\mathrm{COV})$ indicated in that table, are smaller in the proposed equation than in the other prediction formulae. However, it should be noted that the proposed equation is based on a rather limited number of test data and range of variability of the parameters studied.

\section{Conclusions}

An experiment was conducted with three I-shaped reinforced concrete (RC) beams and four I-shaped prestressed reinforced concrete (PRC) beams to investigate the effect of various parameters on maximum shear crack width and the shear crack distribution. The major variables used were prestressing force, side concrete cover, stirrup spacing, type of stirrup and amount of longitudinal reinforcement. Further, equations for the prediction of shear crack spacing and shear crack width in RC and PRC members are proposed. The following conclusions can be drawn from this study:

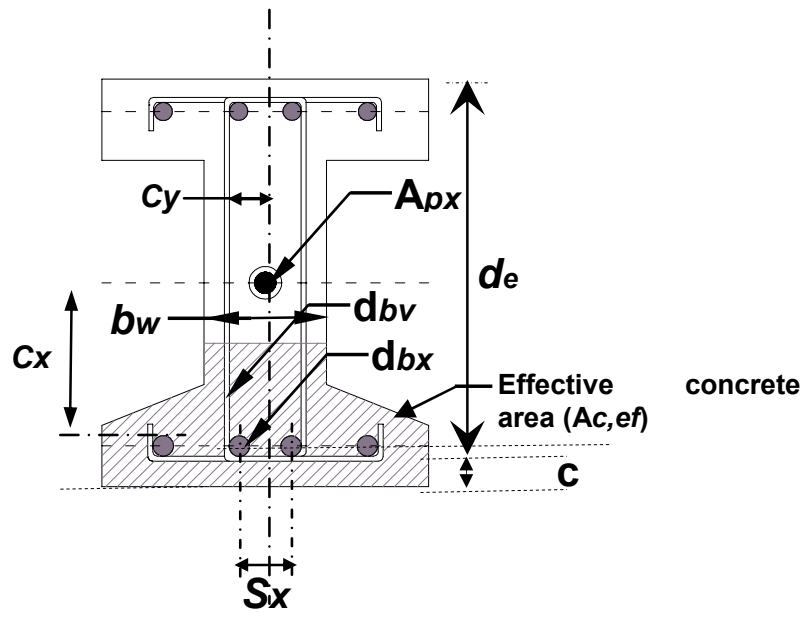

(b) I-shaped beam

Fig. 16 Parameters influencing shear crack spacing. 
Table 6 Comparison of measured and calculated crack spacing.

\begin{tabular}{|l|c|c|c|c|c|c|c|}
\hline \multirow{2}{*}{ Beam } & \multicolumn{2}{|c|}{$\begin{array}{c}\text { Calculated crack } \\
\text { spacing }\end{array}$} & \multicolumn{2}{c|}{ Ratio cal/exp } & \multicolumn{2}{c|}{ Diagonal crack spacing (mm) } \\
\cline { 2 - 8 } & Smx & Smy & $\begin{array}{c}\text { Ratio } \\
\text { Smx }\end{array}$ & $\begin{array}{c}\text { Ratio } \\
\text { Smy }\end{array}$ & $\begin{array}{c}\text { Sm } \theta, \\
\text { Cal }\end{array}$ & $\begin{array}{c}\text { Sm } \theta, \\
\text { Exp }\end{array}$ & $\begin{array}{c}\text { Ratio: } \\
\text { Exp/Cal }\end{array}$ \\
\hline IRC-1 & 158.96 & 104.62 & 1.0 & 1.0 & 89.24 & 92.92 & 1.0 \\
\hline IRC-2 & 158.96 & 72.94 & 0.7 & 0.3 & 70.72 & $173.73^{*}$ & 0.4 \\
\hline IRC-3 & 165.87 & 104.62 & 0.8 & 0.7 & 90.74 & 127.59 & 0.7 \\
\hline IPRC-1 & 165.87 & 104.62 & 0.8 & 0.5 & 88.56 & 147.54 & 0.6 \\
\hline IPRC-2 & 165.87 & 162.97 & 0.8 & 1.3 & 120.08 & 107.91 & 1.1 \\
\hline IPRC-3 & 165.87 & 168.56 & 0.9 & 1.4 & 122.67 & 101.94 & 1.2 \\
\hline IPRC-4 & 152.85 & 104.62 & 0.5 & 0.7 & 86.59 & 137.99 & 0.6 \\
\hline
\end{tabular}

Table 7 Statistical analysis of ratio between measured values and calculated values $\left(w_{\text {exp }} / w_{\text {cal }}\right)$.

\begin{tabular}{|c|c|c|c|c|c|c|}
\hline \multirow{2}{*}{ Researcher/s } & \multicolumn{3}{|c|}{ IRC-1 } & \multicolumn{3}{|c|}{ IPRC-1 } \\
\hline & Avg & Std & $\mathrm{COV} \%$ & Avg & Std & COV $\%$ \\
\hline $\begin{array}{c}\text { CEB-FIP } \\
\text { Model Code } \\
(1978)\end{array}$ & 0.754 & 0.28 & 37.8 & 0.856 & 0.23 & 27.0 \\
\hline $\begin{array}{l}\text { Hassan et al., } \\
\text { (1991) }\end{array}$ & 0.491 & 0.22 & 45.5 & 0.555 & 0.23 & 40.5 \\
\hline $\begin{array}{c}\text { Fukuyama } e t \\
\text { al., (2000) }\end{array}$ & 0.208 & 0.08 & 37.8 & 0.249 & 0.06 & 27.0 \\
\hline $\begin{array}{c}\text { Shinomiya et } \\
\text { al., (2002) }\end{array}$ & 0.637 & 0.24 & 37.8 & 0.761 & 0.20 & 27.0 \\
\hline $\begin{array}{l}\text { Piyamahant } \\
\text { (2002) }\end{array}$ & 0.679 & 0.36 & 53.0 & 0.744 & 0.37 & 50.3 \\
\hline Proposed & 0.619 & 0.23 & 37.8 & 0.750 & 0.20 & 27.0 \\
\hline
\end{tabular}

Avg. - average value

Std. - standard deviation

COV\% - Correlation of variance

(1) The prestressing force provided in PRC beams increases their shear cracking load compared to RC beams. However, after the initial formation of shear cracks, the effect of this prestressing force was not pronounced. At a same level of shear force, a greater prestressing force tended to decrease shear crack widths and stirrup strains. The compressive stress in the concrete due to prestressing force at the centroid of the section had some effect on the relationship between shear crack width and stirrup strain in PRC beams.

(2) The presence of a prestressing tendon at the centroid of the beam section helps with resistance to the externally applied load by means of dowel action. Beams with a prestressing tendon but without prestressing force exhibited a smaller shear crack width than $\mathrm{RC}$ beams at the same level of shear force. The prestressing tendon at the mid-depth of the section acts as longitudinal reinforcement to restrain the opening of crack width in the longitudinal direction, thereby reducing the shear crack width.

(3) Stirrup strain was found to be the most important
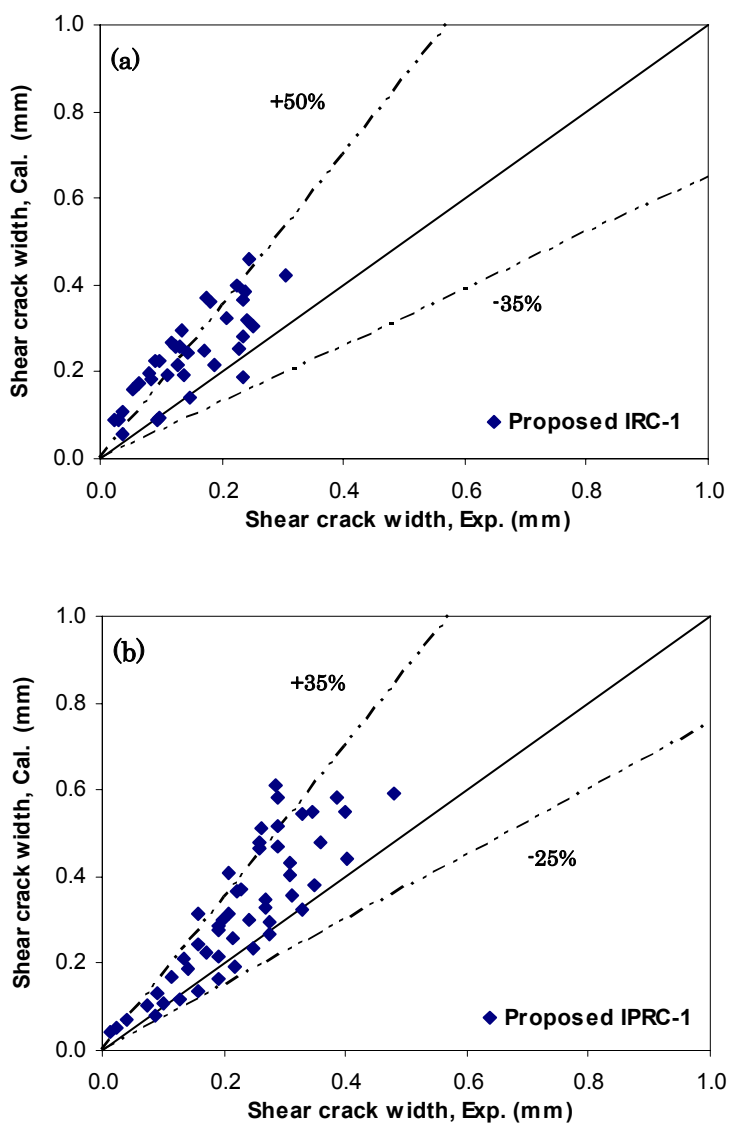

Fig. 17 Accuracy of proposed equation.

factor affecting shear crack width in both RC and PRC beams. The relationship between shear crack width and stirrup strain for deformed stirrups was linear, while it was non-linear (polynomial curve) in the case of plain stirrups. Further, due to the poor bonding between stirrup and concrete in the case of plain stirrups, the shear crack displacement increased in the stirrup direction and so the shear crack width was greater.

(4) Increasing the amount of side concrete cover resulted in a larger shear crack width at the same stirrup strain level. However, owing to the extraordinary crack pattern observed in the beam tested in this study, further investigation is needed to fully clarify the effect of side concrete cover on shear 
crack width.

(5) The amount of tension reinforcement and the stirrup spacing were found to have an insignificant effect on maximum shear crack width in PRC beams with a prestressing force of $375 \mathrm{kN}$.

(6) By considering the above investigated parameters as variables, a simplified shear crack spacing model and an equation for predicting shear crack width in RC and PRC members were proposed. The shear crack widths computed from the proposed equation showed better correlation with the test results compared to other prediction formulae.

\section{References}

ACI-ASCE Committee 423, (1999). "State-of-the-art report on partially prestressed Concrete, ACI 423.5R99." American Concrete Institute, Farmington Hills, Michigan.

ACI Committee 318, (2002). "Building code requirement for reinforced concrete (ACI 318-02) and commentary (318R-02)." American Concrete Institute, Farmington Hills, Michigan.

Adebar, P. and Leeuwen J. V. (1999). "Side-face reinforcement for flexural and diagonal cracking in large concrete beams." ACI Structural Journal, 96(5), 693-704.

Bhide, S. B. and Collins, M. P. (1989). "Influence of axial tension on the shear capacity of reinforced concrete members." ACI Structural Journal, 86(5), 570-581.

Belarbi, A. and Hsu, T. T. C. (1990). "Stirrup stresses in reinforced concrete beams." ACI Structural Journal, 87(5), 530-538.

Bentz, E. C. (2000). "Sectional analysis of reinforced concrete members." Dissertation (Ph.D). University of Toronto, Canada.

Comité Euro International Du Béton, (1978). “CEB-FIP model code for concrete structures." 3rd Edition, Comité Euro-International du Béton/Fédération Internationale de la Précontrainte, Paris.

Comité Euro International Du Béton, (1990). “CEB-FIP model code 1990." Thomas Telford Service Ltd., London.

De Silva, G. S. Y. (2005). "Investigation of shear cracking behavior of partially prestressed concrete beams." Dissertation (M. Eng), Saitama University, Japan.

Fukuyama, H., Suwada, H., Iso, M., Matsuzaki, Y., Nakano, K. and Kasahara, M. (2000). "Evaluation of damage limit state of RC element due to shear crack width." Proceedings of Architectural Institute of Japan (AIJ), (C-2), 13-14. (in Japanese)

Frosch, R. J. (1999). "Another look at cracking and crack control in reinforced concrete." ACI Structural Journal, 96(3), 437-442.

Hsiung, W. and Frantz, G. C. (1985). "Transverse stirrup spacing in R/C beams." Journal of Structural Engineering, ASCE, 111(2), 353-362.
Hassan, H. M., Farghaly, S. A. and Ueda, T. (1991). "Displacement at shear crack in beams with shear reinforcement under static and fatigue loadings." Proceedings of JSCE, 15(433), 215-222.

Japan Society of Civil Engineers, (2002). "Standard specification for design and construction of concrete structures." Part 1 (Design).

JSCE Committee of Damage Evaluation of Structural Performance on Tarui Viaduct, (2005). "Mid-term report on damage evaluation of structural performance on Tarui Viaduct." Tokyo: Japan Society of Civil Engineers (JSCE).

Oh, B. H. and Kang, Y. J. (1987). "New formulas for maximum crack width and crack spacing in reinforced concrete flexural members." $A C I$ Structural Journal, 84(10), 103-112.

Oh, B. H. and Kim K. S. (2004). "Shear behavior of full-scale post-tensioned prestressed concrete bridge girders.” ACI Structural Journal, 101(2), 176-182.

Piyamahant, S. (2002). "Shear behavior of reinforced concrete beams with a small amount of web reinforcement." Dissertation (M.Eng), Kochi University of Technology, Japan.

Piyasena, R., Loo, Yew-Chaye. and Fragomeni, S. (2004). "Factors influencing spacing and width of cracks in reinforced concrete; New prediction formulae." Journal of Advances in Structural Engineering, 7(1), 49-60.

Kakuta, Y. et al., (1970). "Maximum crack width of reinforced concrete", Concrete Journal, 8(9), 1-10. (in Japanese)

Krishna Mohan Rao, S. V. and Dilger, W. H. (1992). "Control of flexural crack width in cracked prestressed concrete members." ACI Structural Journal, 89(2), 127-138.

Shinomiya, K. and Watanabe, F. (2002). "Study on prediction of shear crack width for reinforced concrete beams." Architectural Institute of Japan (AIJ), (C-2), 295-296. (in Japanese)

Tompos, E. J. and Frosch, R. J. (2002). "Influence of beam size, longitudinal reinforcement, and stirrup effectiveness on concrete shear strength." $A C I$ Structural Journal, 99(5), 559-567.

Yoon, Y. S., Cook, W. D. and Mitchell, D. (1996). "Minimum shear reinforcement in normal, medium, and high-strength concrete beams." ACI Structural Journal, 93(5), 576-584.

Witchukreangkrai, E., Mutsuyoshi, H., Kuraoka, M. and Oshiro, T. (2004). "Control of diagonal cracking in partially prestressed concrete beams." Proceedings of Japan Concrete Institute (JCI), 26(2), 727-732.

Zararis, P. D. and Papadakis, G. C. (2001). "Diagonal shear failure and size effect in RC beams without web reinforcement." Journal of Structural Engineering, ASCE, 127(7), 733-741.

Zararis, P. D. (2003). "Shear strength and minimum shear reinforcement of RC slender beams." $A C I$ Structural Journal, 100(2), 203-214. 